\title{
Colonialidad del poder, EUROCENTRISMO Y AMÉRICA LATINA* **
}

$\mathrm{L}$ a globalización en curso es, en primer término, la culminación de un proceso que comenzó con la constitución de América y la del capitalismo colonial / moderno y eurocentrado como un nuevo patrón de poder mundial. Uno de los ejes fundamentales de ese patrón de poder es la clasificación social de la población mundial sobre la idea de raza,

* El presente artículo fue publicado originalmente en: Quijano, Aníbal 2000 "Colonialidad del poder, eurocentrismo y América Latina” en Lander, Edgardo (comp.) La colonialidad del saber: eurocentrismo y ciencias sociales. Perspectivas latinoamericanas (Buenos Aires: CLACSO) p. 246. En: <http://bibliotecavirtual.clacso.org.ar/ar/libros/lander/quijano.rtf $>$.

** Quiero agradecer, principalmente, a Edgardo Lander y a Walter Mignolo, por su ayuda en la revisión de este artículo. Y a un comentarista, cuyo nombre ignoro, por sus útiles críticas a una versión anterior. Ellos, por supuesto, no son responsables de los errores y limitaciones del texto. una construcción mental que expresa la experiencia básica de la dominación colonial y que desde entonces permea las dimensiones más importantes del poder mundial, incluyendo su racionalidad específica, el eurocentrismo. Dicho eje tiene, pues, origen y carácter colonial, pero ha probado ser más duradero y estable que el colonialismo en cuya matriz fue establecido. Implica, en consecuencia, un elemento de colonialidad en el patrón de poder hoy mundialmente hegemónico. En lo que sigue, el propósito principal es abrir algunas de las cuestiones teóricamente necesarias acerca de las implicancias de esa colonialidad del poder respecto de la historia de América Latina ${ }^{1}$.

1 Sobre el concepto de colonialidad del poder, véase: "Colonialidad y modernidad / racionalidad" (Quijano, 1991a). 


\section{AMÉRICA Y EL NUEVO PATRóN DE PODER MUNDIAL}

América se constituyó como el primer espacio / tiempo de un nuevo patrón de poder de vocación mundial y, de ese modo y por eso, como la primera identidad de la modernidad. Dos procesos históricos convergieron y se asociaron en la producción de dicho espacio / tiempo y se establecieron como los dos ejes fundamentales del nuevo patrón de poder. De una parte, la codificación de las diferencias entre conquistadores y conquistados en la idea de raza, es decir, una supuesta diferente estructura biológica que ubicaba a los unos en situación natural de inferioridad respecto de los otros. Esa idea fue asumida por los conquistadores como el principal elemento constitutivo, fundante, de las relaciones de dominación que la conquista imponía. Sobre esa base, en consecuencia, fue clasificada la población de América, y del mundo después, en dicho nuevo patrón de poder. De otra parte, la articulación de todas las formas históricas de control del trabajo, de sus recursos y de sus productos, en torno del capital y del mercado mundial ${ }^{2}$.

2 Ver "Americanity as a Concept or the Americas in the Modern World-System" (Quijano y Wallerstein, 1992). También, la entrevista a Aníbal Quijano “Amé-

\section{RAZA, UNA CATEGORÍA MENTAL DE LA MODERNIDAD}

La idea de raza, en su sentido moderno, no tiene historia conocida antes de América ${ }^{3}$. Quizás se originó como referencia a las diferencias fenotípicas entre conquistadores y conquistados, pero lo que importa es que muy pronto fue construida como referencia a supuestas estructuras biológicas diferenciales entre esos grupos.

La formación de relaciones sociales fundadas en dicha idea produjo en América identidades sociales históricamente nuevas: indios, negros y mestizos, y redefinió otras. Así, términos como español y portugués, y más tarde europeo, que hasta entonces indicaban solamente procedencia geográfica o país de origen, desde entonces cobraron también, en referencia a las nuevas identidades, una connotación racial. Y en la medida en que las relaciones sociales que

rica, el capitalismo y la modernidad nacieron el mismo día" (ILLA, 1991). Sobre el concepto de espacio / tiempo, ver de Wallerstein (1997) "El espacio / tiempo como base del conocimiento".

3 Sobre esta cuestión y sobre los posibles antecedentes de la idea de raza antes de América, remito a mi “'Raza', 'etnia' y 'nación' en Mariátegui: cuestiones abiertas" (Quijano, 1992a). 
estaban configurándose eran relaciones de dominación, tales identidades fueron asociadas a las jerarquías, lugares y roles sociales correspondientes, como constitutivas de ellas y, en consecuencia, al patrón de dominación colonial que se imponía. En otros términos, raza e identidad racial fueron establecidas como instrumentos de clasificación social básica de la población.

Con el tiempo, los colonizadores codificaron como color los rasgos fenotípicos de los colonizados y lo asumieron como la característica emblemática de la categoría racial. Esa codificación fue inicialmente establecida, probablemente, en el área britano-americana. Los negros eran allí no solamente los explotados más importantes, pues la parte principal de la economía reposaba en su trabajo. Eran, sobre todo, la raza colonizada más importante, ya que los indios no formaban parte de esa sociedad colonial. En consecuencia, los dominantes se llamaron a sí mismos blancos ${ }^{4}$.

4 La invención de la categoría de color -primero como la más visible indicación de raza, luego simplemente como el equivalente de ella-, tanto como la invención de la particular categoría de blanco, requieren aún una investigación histórica más exhaustiva. En todo caso, muy probablemente fueron inventos brita-
En América, la idea de raza fue un modo de otorgar legitimidad a las relaciones de dominación impuestas por la conquista. La posterior constitución de Europa como nueva id-entidad después de América y la expansión del colonialismo europeo sobre el resto del mundo llevaron a la elaboración de la perspectiva eurocéntrica de conocimiento y con ella a la elaboración teórica de la idea de raza como naturalización de esas relaciones coloniales de dominación entre europeos y no-europeos. Históricamente, eso significó una nueva manera de

no-americanos, ya que no hay huellas de esas categorías en las crónicas y otros documentos de los primeros cien años del colonialismo ibérico en América. Para el caso britano-americano existe una extensa bibliografía: Allen (1994); Jacobson (1998), entre los más importantes. El problema es que ésta ignora lo sucedido en la América ibérica. Debido a eso, para esta región carecemos aún de información suficiente sobre este aspecto específico. Por eso ésta sigue siendo una cuestión abierta. Es muy interesante que a pesar de que quienes habrían de ser europeos en el futuro, conocían a los futuros africanos desde la época del imperio romano, inclusive los íberos que eran más o menos familiares con ellos mucho antes de la Conquista, nunca se pensó en ellos en términos raciales antes de la aparición de América. De hecho, raza es una categoría aplicada por primera vez a los "indios", no a los "negros". De este modo, raza apareció mucho antes que color en la historia de la clasificación social de la población mundial. 
legitimar las ya antiguas ideas y prácticas de relaciones de superioridad / inferioridad entre dominados y dominantes. Desde entonces ha demostrado ser el más eficaz y perdurable instrumento de dominación social universal, pues de él pasó a depender inclusive otro igualmente universal, pero más antiguo, el intersexual o de género: los pueblos conquistados y dominados fueron situados en una posición natural de inferioridad y, en consecuencia, también sus rasgos fenotípicos, así como sus descubrimientos mentales y culturales ${ }^{5}$. De ese modo, raza se convirtió en el primer criterio fundamental para la distribución de la población mundial en los rangos, lugares y roles en la estructura de poder de la nueva sociedad. En otros términos, en el modo básico de clasificación social universal de la población mundial.

5 La idea de raza es, literalmente, un invento. No tiene nada que ver con la estructura biológica de la especie humana. En cuanto a los rasgos fenotípicos, éstos se hallan obviamente en el código genético de los individuos y grupos, y en ese sentido específico son biológicos. Sin embargo, no tienen ninguna relación con ninguno de los subsistemas y procesos biológicos del organismo humano, incluyendo por cierto aquellos implicados en los subsistemas neurológicos y mentales, y sus funciones. Véase: Mark (1994) y “¡Qué tal raza!” (Quijano, 1999a).

\section{EL CAPITALISMO: LA NUEVA ESTRUCTURA DE CONTROL DEL TRABAJO}

De otro lado, en el proceso de constitución histórica de América, todas las formas de control y de explotación del trabajo y de control de la producción-apropiación-distribución de productos fueron articuladas alrededor de la relación capital-salario (en adelante capital) y del mercado mundial. Quedaron incluidas: la esclavitud, la servidumbre, la pequeña producción mercantil, la reciprocidad y el salario. En tal ensamblaje, cada una de dichas formas de control del trabajo no era una mera extensión de sus antecedentes históricos. Todas eran histórica y sociológicamente nuevas. En primer lugar, porque fueron deliberadamente establecidas y organizadas para producir mercaderías para el mercado mundial. En segundo lugar, porque no existían sólo de manera simultánea en el mismo espacio / tiempo, sino todas y cada una articuladas al capital y a su mercado, y por ese medio entre sí. Configuraron así un nuevo patrón global de control del trabajo, a su vez un elemento fundamental de un nuevo patrón de poder, del cual eran de modo conjunto e individual dependientes histórico-estructuralmente. Esto es, no sólo por su lugar y función como partes subordinadas de una totalidad, sino porque sin per- 
der sus respectivas características específicas y sin perjuicio de las discontinuidades de sus relaciones con el orden conjunto y entre ellas mismas, su movimiento histórico dependía en adelante de su pertenencia al patrón global de poder. En tercer lugar, y como consecuencia, para colmar las nuevas funciones cada una de ellas desarrolló nuevos rasgos y nuevas configuraciones histórico-estructurales.

En la medida en que aquella estructura de control del trabajo, de recursos y de productos consistía en la articulación conjunta de todas las respectivas formas históricamente conocidas, se establecía, por primera vez en la historia conocida, un patrón global de control del trabajo, de sus recursos y de sus productos. $\mathrm{Y}$ en tanto que se constituía en torno a y en función del capital, su carácter de conjunto se establecía también con carácter capitalista. De ese modo se establecía una nueva, original y singular estructura de relaciones de producción en la experiencia histórica del mundo: el capitalismo mundial.

\section{Colonialidad DeL PODER Y CAPITALISMO MUNDIAL}

Las nuevas identidades históricas, producidas sobre la base de la idea de raza, fueron asocia- das a la naturaleza de los roles y lugares en la nueva estructura global de control del trabajo. Así, ambos elementos, raza y división del trabajo, quedaron estructuralmente asociados $\mathrm{y}$ reforzándose mutuamente, a pesar de que ninguno de los dos era necesariamente dependiente el uno del otro para existir o para cambiar.

De ese modo se impuso una sistemática división racial del trabajo. En el área hispana, la Corona de Castilla decidió temprano el cese de la esclavitud de los indios, para prevenir su total exterminio. Entonces fueron confinados a la servidumbre. A los que vivían en sus comunidades, les fue permitida la práctica de su antigua reciprocidad -por ejemplo, el intercambio de fuerza de trabajo y de trabajo sin mercado- como una manera de reproducir su fuerza de trabajo en tanto siervos. En algunos casos, la nobleza india, una reducida minoría, fue eximida de la servidumbre y recibió un trato especial, debido a sus roles como intermediaria con la raza dominante y le fue también permitido participar en algunos de los oficios en los cuales eran empleados los españoles que no pertenecían a la nobleza. En cambio, los negros fueron reducidos a la esclavitud. Los españoles y los portugueses, como raza dominante, podían recibir salario, ser comerciantes independientes, artesanos 
independientes o agricultores independientes, en suma, productores independientes de mercancías. No obstante, sólo los nobles podían participar en los puestos altos y medios de la administración colonial, civil y militar.

Desde el siglo XVIII, en la América hispánica muchos de los mestizos de españoles y mujeres indias, ya un estrato social extendido e importante en la sociedad colonial, comenzaron a participar en los mismos oficios y actividades que ejercían los ibéricos que no eran nobles. En menor medida y sobre todo en actividades de servicio o que requerían de talentos o habilidades especiales (música, por ejemplo), también los más "ablancados" entre los mestizos de mujeres negras e ibéricos (españoles o portugueses), pero tardaron en legitimar sus nuevos roles ya que sus madres eran esclavas. La distribución racista del trabajo al interior del capitalismo colonial / moderno se mantuvo a lo largo de todo el período colonial.

En el curso de la expansión mundial de la dominación colonial por parte de la misma raza dominante -los blancos (o a partir del siglo XVIII en adelante, los europeos)- fue impuesto el mismo criterio de clasificación social a toda la población mundial a escala global. En consecuencia, nuevas identidades históricas y sociales fueron producidas: amarillos y aceitu- nados (u oliváceos) fueron sumados a blancos, indios, negros y mestizos. Dicha distribución racista de nuevas identidades sociales fue combinada, tal como había sido tan exitosamente lograda en América, con una distribución racista del trabajo y de las formas de explotación del capitalismo colonial. Esto se expresó, sobre todo, en una cuasi exclusiva asociación de la blanquitud social con el salario y por supuesto con los puestos de mando de la administración colonial.

Así, cada forma de control del trabajo estuvo articulada con una raza particular. Consecuentemente, el control de una forma específica de trabajo podía ser al mismo tiempo el control de un grupo específico de gente dominada. Una nueva tecnología de dominación / explotación, en este caso raza / trabajo, se articuló de manera que apareciera como naturalmente asociada. Lo cual, hasta ahora, ha sido excepcionalmente exitoso.

\section{COLONIALIDAD Y EUROCENTRAMIENTO DEL CAPITALISMO MUNDIAL}

La privilegiada posición ganada con América para el control del oro, la plata y otras mercancías producidas por medio del trabajo gratuito de indios, negros y mestizos, y su ventajo- 
sa ubicación en la vertiente del Atlántico por donde, necesariamente, tenía que hacerse el tráfico de esas mercancías para el mercado mundial, otorgó a dichos blancos una ventaja decisiva para disputar el control del tráfico comercial mundial. La progresiva monetización del mercado mundial que los metales preciosos de América estimulaban y permitían, así como el control de tan ingentes recursos, hizo que a tales blancos les fuera posible el control de la vasta red preexistente de intercambio comercial que incluía, sobre todo, China, India, Ceylán, Egipto, Siria, los futuros Lejano y Medio Oriente. Eso también les hizo posible concentrar el control del capital comercial, del trabajo y de los recursos de producción en el conjunto del mercado mundial. Y todo ello fue, posteriormente, reforzado y consolidado a través de la expansión de la dominación colonial blanca sobre la diversa población mundial.

Como es sabido, el control del tráfico comercial mundial por los grupos dominantes, nuevos o no, en las zonas del Atlántico donde tenían sus sedes, impulsó un nuevo proceso de urbanización en esos lugares, la expansión del tráfico comercial entre ellos, y de ese modo la formación de un mercado regional crecientemente integrado y monetizado gracias al flujo de metales preciosos procedentes de América.
Una región históricamente nueva se constituía como una nueva id-entidad geocultural: Europa y más específicamente Europa Occidental $^{6}$. Esa nueva identidad geocultural, emergía como la sede central del control del mercado mundial. En el mismo movimiento histórico se producía también el desplazamiento de hegemonía desde las costas del Mediterráneo y desde las costas ibéricas, hacia las del Atlántico Noroccidental.

Esa condición de sede central del nuevo mercado mundial no permite explicar por sí misma, o por sí sola, por qué Europa se convirtió también, hasta el siglo XIX y virtualmente hasta la crisis mundial alrededor de 1870, en la sede central del proceso de mercantilización de la fuerza de trabajo, es decir del desarrollo de la relación capital-salario como forma específica de control del trabajo, de sus recursos y de sus productos. Mientras, en cambio, todo el resto de las regiones y poblaciones incorporadas al nuevo mercado mundial y colonizadas o en curso de colonización bajo dominio europeo, permanecían básicamente bajo relaciones no-salariales de trabajo, aunque, desde luego

6 Fernando Coronil (1996) ha discutido la construcción de la categoría Occidente como parte de la formación de un poder global. 
ese trabajo, sus recursos y sus productos, se articulaban en una cadena de transferencia de valor y de beneficios cuyo control correspondía a Europa Occidental. En las regiones noeuropeas, el trabajo asalariado se concentraba cuasi exclusivamente entre los blancos.

No hay nada en la relación social misma del capital, o en los mecanismos del mercado mundial, en general en el capitalismo, que implique la necesariedad histórica de la concentración, no sólo, pero sobre todo en Europa, del trabajo asalariado y después, precisamente sobre esa base, de la concentración de la producción industrial capitalista durante más de dos siglos. Habría sido perfectamente factible, como lo demuestra el hecho de que así ocurriera en verdad después de 1870, el control europeo-occidental del trabajo asalariado de cualquier sector de la población mundial. Y, probablemente, más beneficioso para los europeo-occidentales. La explicación debe ser, pues, buscada en otra parte de la historia. El hecho es que ya desde el comienzo mismo de América, los futuros europeos asociaron el trabajo no pagado o no-asalariado con las razas dominadas, porque eran razas inferiores. $\mathrm{El}$ vasto genocidio de los indios en las primeras décadas de la colonización no fue causado principalmente por la violencia de la conquista, ni por las enfermedades que los conquistadores portaban, sino porque tales indios fueron usados como mano de obra desechable, forzados a trabajar hasta morir. La eliminación de esa práctica colonial no culmina, de hecho, sino con la derrota de los encomenderos, a mediados del siglo XVI. La subsiguiente reorganización política del colonialismo ibérico implicó una nueva política de reorganización poblacional de los indios y de sus relaciones con los colonizadores. Pero no por eso los indios fueron en adelante trabajadores libres y asalariados. En adelante, fueron adscritos a la servidumbre no pagada. La servidumbre de los indios en América no puede ser, por otro lado, simplemente equiparada a la servidumbre en el feudalismo europeo, puesto que no incluía la supuesta protección de ningún señor feudal, ni siempre, ni necesariamente, la tenencia de una porción de tierra para cultivar, en lugar de salario. Sobre todo antes de la Independencia, la reproducción de la fuerza de trabajo del siervo indio se hacía en las comunidades. Pero inclusive más de cien años después de la Independencia, una parte amplia de la servidumbre india estaba obligada a reproducir su fuerza de trabajo por su propia cuenta ${ }^{7}$. Y la

7 Eso fue lo que, según comunicación personal, encontró Alfred Metraux, el conocido antropólogo francés, a fines de los años cincuenta en el Sur del Perú; y 
otra forma de trabajo no-asalariado, o no pagado simplemente, el trabajo esclavo, fue adscrita, exclusivamente, a la población traída desde la futura África y llamada negra.

La clasificación racial de la población, y la temprana asociación de las nuevas identidades raciales de los colonizados con las formas de control no pagado, no asalariado, del trabajo, desarrolló entre los europeos o blancos la específica percepción de que el trabajo pagado era privilegio de los blancos. La inferioridad racial de los colonizados implicaba que no eran dignos del pago de salario. Estaban naturalmente obligados a trabajar en beneficio de sus amos. No es muy difícil encontrar, hoy mismo, esa actitud extendida entre los terratenientes blancos de cualquier lugar del mundo. Y el menor salario de las razas inferiores por igual trabajo que el de los blancos, en los actuales centros capitalistas, no podría ser, tampoco, explicado al margen de la cla-

lo mismo que también encontré en 1963, en el Cusco: un peón indio obligado a viajar desde su aldea, en La Convención, hasta la ciudad, para cumplir su turno de servir durante una semana a sus patrones. Pero éstos no le proporcionaban vivienda, ni alimento, ni, desde luego, salario. Metraux proponía que esa situación estaba más cercana del colonato romano del siglo IV d.C., que del feudalismo europeo. sificación social racista de la población del mundo. En otros términos, por separado de la colonialidad del poder capitalista mundial. El control del trabajo en el nuevo patrón de poder mundial se constituyó, así, articulando todas las formas históricas de control del trabajo en torno de la relación capital-trabajo asalariado, y de ese modo bajo el dominio de ésta. Pero dicha articulación fue constitutivamente colonial, pues se fundó, primero, en la adscripción de todas las formas de trabajo no pagadas a las razas colonizadas, originalmente indios, negros y de modo más complejo, los mestizos en América y, más tarde, a las demás razas colonizadas en el resto del mundo: oliváceos y amarillos. Y, segundo, en la adscripción del trabajo pagado, asalariado, a la raza colonizadora, los blancos.

Esa colonialidad del control del trabajo determinó la distribución geográfica de cada una de las formas integradas en el capitalismo mundial. En otros términos, decidió la geografía social del capitalismo: el capital, en tanto que relación social de control del trabajo asalariado, era el eje en torno del cual se articulaban todas las demás formas de control del trabajo, de sus recursos y de sus productos. Eso lo hacía dominante sobre todas ellas y daba carácter capitalista al conjunto de dicha estructura de con- 
trol del trabajo. Pero al mismo tiempo, dicha relación social específica fue geográficamente concentrada en Europa, sobre todo, y socialmente entre los europeos en todo el mundo del capitalismo. Y en esa medida, y manera, Europa y lo europeo se constituyeron en el centro del mundo capitalista.

Cuando Raúl Prebisch ${ }^{8}$ acuñó la célebre imagen de "centro-periferia", para describir la configuración mundial del capitalismo después de la Segunda Guerra Mundial, apuntó, sabiéndolo o sin saber, al núcleo principal del carácter histórico del patrón de control del trabajo, de sus recursos y de sus productos, que formaba parte central del nuevo patrón mundial de poder constituido a partir de América. El capitalismo mundial fue, desde la partida, colonial / moderno y eurocentrado. Sin relación clara con esas específicas características históricas del capitalismo, el propio concepto de "moderno sistema-mundo" desarrollado, principalmente, por Immanuel Wallerstein ${ }^{9}$ a partir de Prebisch y del concepto marxiano de

8 Ver: "Commercial Policy in the Underdeveloped Countries" (Prebisch, 1959); Prebisch (1960); "The Economics of Prebisch and ECLA" (Baer, 1962).

9 Ver, principalmente: Wallerstein (1989); Hopkins y Wallerstein (1982). capitalismo mundial, no podría ser apropiada y plenamente entendido.

\section{NUEVO PATRÓN DE PODER MUNDIAL Y NUEVA INTERSUB JETIVIDAD MUNDIAL}

Ya en su condición de centro del capitalismo mundial, Europa no solamente tenía el control del mercado mundial, sino que pudo imponer su dominio colonial sobre todas las regiones y poblaciones del planeta, incorporándolas al "sistema-mundo" que así se constituía y a su específico patrón de poder. Para tales regiones y poblaciones, eso implicó un proceso de re-identificación histórica, pues desde Europa les fueron atribuidas nuevas identidades geoculturales. De ese modo, después de América y de Europa, fueron establecidas África, Asia y eventualmente Oceanía. En la producción de esas nuevas identidades, la colonialidad del nuevo patrón de poder fue, sin duda, una de las más activas determinaciones. Pero las formas y el nivel de desarrollo político y cultural, más específicamente intelectual, en cada caso, jugaron también un papel de primer plano. Sin esos factores, la categoría Oriente no habría sido elaborada como la única con la dignidad suficiente para ser el Otro -aunque, por definición, inferior- 
de Occidente, sin que alguna equivalente fuera acuñada para indios o negros ${ }^{10}$. Pero esta misma omisión pone al descubierto que esos otros factores actuaron también dentro del patrón racista de clasificación social universal de la población mundial.

La incorporación de tan diversas y heterogéneas historias culturales a un único mundo dominado por Europa, significó para ese mundo una configuración cultural e intelectual, en suma, intersubjetiva, equivalente a la articulación de todas las formas de control del trabajo en torno del capital, para establecer el capitalismo mundial. En efecto, todas las experiencias, historias, recursos y productos culturales, terminaron también articulados en un sólo orden cultural global en torno de la hegemonía europea u occidental. En otros términos, como parte del nuevo patrón de poder mundial, Europa también concentró bajo su hegemonía el control de todas las formas de control de la subjetividad, de la cultura, y en especial del conocimiento, de la producción del conocimiento.

10 Sobre el proceso de producción de nuevas identidades histórico-geoculturales, véanse: O'Gorman (1954); Rabasa (1993); Dussel (1995); Mudimbe (1988); Tilly (1990); Said (1979); Coronil (1996).
En el proceso que llevó a ese resultado, los colonizadores ejercieron diversas operaciones que dan cuenta de las condiciones que llevaron a la configuración de un nuevo universo de relaciones intersubjetivas de dominación entre Europa y lo europeo y las demás regiones y poblaciones del mundo, a las cuales les estaban siendo atribuidas, en el mismo proceso, nuevas identidades geoculturales. En primer lugar, expropiaron a las poblaciones colonizadas -entre sus descubrimientos culturales- aquellos que resultaban más aptos para el desarrollo del capitalismo y en beneficio del centro europeo. En segundo lugar, reprimieron tanto como pudieron; es decir en variables medidas según los casos, las formas de producción de conocimiento de los colonizados, sus patrones de producción de sentidos, su universo simbólico, sus patrones de expresión y de objetivación de la subjetividad. La represión en este campo fue conocidamente más violenta, profunda y duradera entre los indios de América ibérica, a los que condenaron a ser una subcultura campesina, iletrada, despojándolos de su herencia intelectual objetivada. Algo equivalente ocurrió en África. Sin duda mucho menor fue la represión en el caso de Asia, en donde, por lo tanto, una parte importante de la historia y de la herencia intelectual, escrita, pudo ser preservada. 
Y fue eso, precisamente, lo que dio origen a la categoría de Oriente. En tercer lugar, forzaron -también en medidas variables en cada casoa los colonizados a aprender parcialmente la cultura de los dominadores en todo lo que fuera útil para la reproducción de la dominación, sea en el campo de la actividad material, tecnológica, como de la subjetiva, especialmente religiosa. Es este el caso de la religiosidad judeocristiana. Todo ese accidentado proceso implicó a largo plazo una colonización de las perspectivas cognitivas, de los modos de producir u otorgar sentido a los resultados de la experiencia material o intersubjetiva, del imaginario, del universo de relaciones intersubjetivas del mundo, de la cultura en suma ${ }^{11}$.

En fin, el éxito de Europa Occidental en convertirse en el centro del moderno sistemamundo, según la apta formulación de Wallerstein, desarrolló en los europeos un rasgo común a todos los dominadores coloniales e im-

11 Acerca de esas cuestiones, ver: Stocking (1968); Young (1995). Ver, también, "Colonialidad y modernidad / racionalidad” (Quijano, 1991a); "Colonialidad del poder, cultura y conocimiento en América Latina” (Quijano, 1997); "Réflexions sur l'Interdisciplinarité, le Développement et les Relations Inter culturelles” (Quijano, 1992b); Gruzinski (1988). periales de la historia, el etnocentrismo. Pero en el caso europeo ese rasgo tenía un fundamento y una justificación peculiar: la clasificación racial de la población del mundo después de América. La asociación entre ambos fenómenos, el etnocentrismo colonial y la clasificación racial universal, ayuda a explicar por qué los europeos fueron llevados a sentirse no sólo superiores a todos los demás pueblos del mundo, sino, en particular, naturalmente superiores. Esa instancia histórica se expresó en una operación mental de fundamental importancia para todo el patrón de poder mundial, sobre todo respecto de las relaciones intersubjetivas que le son hegemónicas y en especial de su perspectiva de conocimiento: los europeos generaron una nueva perspectiva temporal de la historia y re-ubicaron a los pueblos colonizados, y a sus respectivas historias y culturas, en el pasado de una trayectoria histórica cuya culminación era Europa ${ }^{12}$. Pero, notablemente, no en una misma línea de continuidad con los europeos, sino en otra categoría naturalmente diferente. Los pueblos colonizados eran razas inferiores y -por elloanteriores a los europeos.

12 Véase: Mignolo (1995); Blaut (1993); Lander (1997). 
Con acuerdo a esa perspectiva, la modernidad y la racionalidad fueron imaginadas como experiencias y productos exclusivamente europeos. Desde ese punto de vista, las relaciones intersubjetivas y culturales entre Europa, es decir Europa Occidental, y el resto del mundo, fueron codificadas en un juego entero de nuevas categorías: OrienteOccidente, primitivo-civilizado, mágico / mítico-científico, irracional-racional, tradicional-moderno. En suma, Europa y no-Europa. Incluso así, la única categoría con el debido honor de ser reconocida como el Otro de $\mathrm{Eu}$ ropa u "Occidente", fue "Oriente". No los "indios" de América, tampoco los "negros" del África. Estos eran simplemente "primitivos". Por debajo de esa codificación de las relaciones entre europeo / no-europeo, raza es, sin duda, la categoría básica ${ }^{13}$. Esa perspectiva binaria, dualista, de conocimiento, peculiar del eurocentrismo, se impuso como mundial-

13 Acerca de las categorías producidas durante el dominio colonial europeo del mundo, existen un buen número de líneas de debate: "estudios de la subalternidad", "estudios postcoloniales", "estudios culturales", "multiculturalismo", entre los actuales. También una floreciente bibliografía demasiado larga para ser aquí citada y con nombres famosos como Guha, Spivak, Said, Bhabha, Hall, entre ellos. mente hegemónica en el mismo cauce de la expansión del dominio colonial de Europa sobre el mundo. No sería posible explicar de otro modo, satisfactoriamente en todo caso, la elaboración del eurocentrismo como perspectiva hegemónica de conocimiento, de la versión eurocéntrica de la modernidad y sus dos principales mitos fundantes: uno, la ideaimagen de la historia de la civilización humana como una trayectoria que parte de un estado de naturaleza y culmina en Europa. Y dos, otorgar sentido a las diferencias entre Europa y no-Europa como diferencias de naturaleza (racial) y no de historia del poder. Ambos mitos pueden ser reconocidos, inequívocamente, en el fundamento del evolucionismo y del dualismo, dos de los elementos nucleares del eurocentrismo.

\section{LA CUESTIÓN DE LA MODERNIDAD}

No me propongo aquí entrar en una discusión detenida de la cuestión de la modernidad y de su versión eurocéntrica. Le he dedicado antes otros estudios y volveré sobre ella después. En particular, no prolongaré este trabajo con una discusión acerca del debate modernidadposmodernidad y su vasta bibliografía. Pero es pertinente para los fines de este trabajo, en 
especial de la parte siguiente, insistir en algunas cuestiones ${ }^{14}$.

El hecho de que los europeos occidentales imaginaran ser la culminación de una trayectoria civilizatoria desde un estado de naturaleza, les llevó también a pensarse como los modernos de la humanidad y de su historia, esto es, como lo nuevo y al mismo tiempo lo más avanzado de la especie. Pero puesto que al mismo tiempo atribuían al resto de la especie la pertenencia a una categoría, por naturaleza, inferior y por eso anterior, esto es, el pasado en el proceso de la especie, los europeos imaginaron también ser no solamente los portadores exclusivos de tal modernidad, sino igualmente sus exclusivos creadores y protagonistas. Lo notable de eso no es que los europeos se imaginaran y pensaran a sí mismos y al resto de la especie de ese modo -eso no es un privilegio de los europeos-, sino el hecho de que fueran capaces de difundir y de establecer esa perspectiva histórica como hegemónica dentro del

14 De mis anteriores estudios, ver, principalmente: "Modernidad, identidad y utopía en América Latina" (Quijano, 1988a); "Colonialidad y modernidad / racionalidad” (Quijano, 1991a); y "Estado-nación, ciudadanía y democracia: cuestiones abiertas" (González y Schmidt, 1998). nuevo universo intersubjetivo del patrón mundial de poder.

Desde luego, la resistencia intelectual a esa perspectiva histórica no tardó en emerger. En América Latina desde fines del siglo XIX, pero se afirmó sobre todo durante el siglo XX y en especial después de la Segunda Guerra Mundial, en vinculación con el debate sobre la cuestión del desarrollo-subdesarrollo. Como ese debate fue dominado durante un buen tiempo por la denominada teoría de la modernización ${ }^{15}$, en sus vertientes opuestas, para sostener que la modernización no implica necesariamente la occidentalización de las sociedades y de las culturas no-europeas, uno de los argumentos más usados fue que la modernidad es un fenómeno de todas las culturas, no sólo de la europea u occidental.

Si el concepto de modernidad es referido, sólo o fundamentalmente, a las ideas de novedad, de lo avanzado, de lo racional-científico, laico, secular, que son las ideas y experiencias normalmente asociadas a ese concepto, no cabe duda de que es necesario admitir que es un fenómeno posible en todas las culturas y

15 Hay una vasta literatura en torno de ese debate. Un sumario puede ser encontrado en mi texto "El fantasma del desarrollo en América Latina” (Quijano, 2000a). 
en todas las épocas históricas. Con todas sus respectivas particularidades y diferencias, todas las llamadas altas culturas (China, India, Egipto, Grecia, Maya-Azteca, Tawantinsuyo) anteriores al actual sistema-mundo, muestran inequívocamente las señales de esa modernidad, incluido lo racional-científico, la secularización del pensamiento, etc. En verdad, a estas alturas de la investigación histórica sería casi ridículo atribuir a las altas culturas noeuropeas una mentalidad mítico-mágica como rasgo definitorio, por ejemplo, en oposición a la racionalidad y a la ciencia como características de Europa, pues aparte de los posibles o más bien conjeturados contenidos simbólicos, las ciudades, los templos y palacios, las pirámides, o las ciudades monumentales, sea Machu Pichu o Boro Budur, las irrigaciones, las grandes vías de trasporte, las tecnologías metalíferas, agropecuarias, las matemáticas, los calendarios, la escritura, la filosofía, las historias, las armas y las guerras, dan cuenta del desarrollo científico y tecnológico en cada una de tales altas culturas, desde mucho antes de la formación de Europa como nueva identidad. Lo más que realmente puede decirse es que, en el actual período, se ha ido más lejos en el desarrollo científico-tecnológico y se han hecho mayores descubrimientos y realizacio- nes, con el papel hegemónico de Europa y, en general, de Occidente.

Los defensores de la patente europea de la modernidad suelen apelar a la historia cultural del antiguo mundo heleno-románico y al mundo del Mediterráneo antes de América, para legitimar su reclamo a la exclusividad de esa patente. Lo que es curioso de ese argumento es que escamotea, primero, el hecho de que la parte realmente avanzada de ese mundo del Mediterráneo, antes de América, área por área de esa modernidad, era islamo-judaica. Segundo, que fue dentro de ese mundo que se mantuvo la herencia cultural grecorromana, las ciudades, el comercio, la agricultura comercial, la minería, la textilería, la filosofía, la historia, cuando la futura Europa Occidental estaba dominada por el feudalismo y su oscurantismo cultural. Tercero que, muy probablemente, la mercantilización de la fuerza de trabajo, la relación capital-salario, emergió, precisamente, en esa área y fue en su desarrollo que se expandió posteriormente hacia el norte de la futura Europa. Cuarto, que solamente a partir de la derrota del Islam y del posterior desplazamiento de la hegemonía sobre el mercado mundial al centro-norte de la futura Europa, gracias a América, comienza también a desplazarse el centro de la actividad cultural a esa 
nueva región. Por eso, la nueva perspectiva geográfica de la historia y de la cultura, que allí es elaborada y que se impone como mundialmente hegemónica, implica, por supuesto, una nueva geografía del poder. La idea misma de Occidente-Oriente es tardía y parte desde la hegemonía británica. ¿O aún hace falta recordar que el meridiano de Greenwich atraviesa Londres y no Sevilla o Venecia? ${ }^{16}$

En ese sentido, la pretensión eurocéntrica de ser la exclusiva productora y protagonista de la modernidad, y de que toda modernización de poblaciones no-europeas es, por lo tanto, una europeización, es una pretensión etnocentrista y a la postre provinciana. Pero, de otro lado, si se admite que el concepto de modernidad se refiere solamente a la racionalidad, a la ciencia, a la tecnología, etc., la cuestión que le estaríamos planteando a la experiencia histórica no sería diferente de la propuesta por el etnocentrismo europeo, el debate consistiría apenas en la disputa por la originalidad y la exclusividad de la propiedad del fenómeno así llamado modernidad, y, en consecuencia, moviéndose en el mismo terreno y según la misma perspectiva del eurocentrismo.

16 Sobre esto, sugiero consultar las agudas observaciones de Robert J. C. Young (1995).
Hay, sin embargo, un conjunto de elementos demostrables que apuntan a un concepto de modernidad diferente, que da cuenta de un proceso histórico específico al actual sistemamundo. En ese concepto no están, obviamente, ausentes sus referencias y sus rasgos anteriores. Pero más bien en tanto y en cuanto forman parte de un universo de relaciones sociales, materiales e intersubjetivas, cuya cuestión central es la liberación humana como interés histórico de la sociedad y también, en consecuencia, su campo central de conflicto. En los límites de este trabajo, me restringiré solamente a adelantar, de modo breve y esquemático, algunas proposiciones $^{17}$.

En primer término, el actual patrón de poder mundial es el primero efectivamente global de la historia conocida. En varios sentidos específicos. Uno, es el primero donde en cada uno de los ámbitos de la existencia social están articuladas todas las formas históricamente conocidas de control de las relaciones sociales correspondientes, configurando en cada área una sola estructura con relaciones sistemáticas entre sus componentes y del mismo modo en su conjunto. Dos, es el primero donde

17 Un debate más detenido en "Modernidad y democracia: intereses y conflictos" (Quijano, 2000b). 
cada una de esas estructuras de cada ámbito de existencia social está bajo la hegemonía de una institución producida dentro del proceso de formación y desarrollo de este mismo patrón de poder. Así, en el control del trabajo, de sus recursos y de sus productos, está la empresa capitalista; en el control del sexo, de sus recursos y productos, la familia burguesa; en el control de la autoridad, sus recursos y productos, el Estado-nación; en el control de la intersubjetividad, el eurocentrismo ${ }^{18}$. Tres, cada una de esas instituciones existe en relaciones de interdependencia con cada una de las otras. Por lo cual el patrón de poder está configurado como un sistema ${ }^{19}$. Cuatro, en fin, este patrón de poder mundial es el primero que cubre a la totalidad de la población del planeta.

En ese específico sentido, la humanidad ac-

18 Acerca de las proposiciones teóricas de esta concepción del poder, ver: "Coloniality of Power and its Institutions” (Quijano, 1999).

19 En el sentido de que las relaciones entre las partes y la totalidad no son arbitrarias y la última tiene hegemonía sobre las partes en la orientación del movimiento del conjunto. No en el sentido sistémico, es decir en que las relaciones de las partes entre sí y con el conjunto son lógico-funcionales. Esto no ocurre sino en las máquinas y en los organismos. Nunca en las relaciones sociales. tual en su conjunto constituye el primer sistema-mundo global históricamente conocido, no solamente un mundo como el que quizás fueron el chino, el hindú, el egipcio, el helénicorománico, el maya-azteca o el tawantinsuyano. Ninguno de esos posibles mundos tuvo en común sino un dominador colonial / imperial y, aunque así se propone desde la visión colonial eurocéntrica, no es seguro que todos los pueblos incorporados a uno de aquellos mundos tuvieran también en común una perspectiva básica respecto de las relaciones entre lo humano y el resto del universo. Los dominadores coloniales de cada uno de esos mundos, no tenían las condiciones, ni probablemente el interés, de homogenizar las formas básicas de existencia social de todas las poblaciones de sus dominios. En cambio, el actual, el que comenzó a formarse con América, tiene en común tres elementos centrales que afectan la vida cotidiana de la totalidad de la población mundial: la colonialidad del poder, el capitalismo y el eurocentrismo. Por supuesto que este patrón de poder, ni otro alguno, puede implicar que la heterogeneidad histórico-estructural haya sido erradicada dentro de sus dominios. Lo que su globalidad implica es un piso básico de prácticas sociales comunes para todo el mundo, y una esfera intersubjetiva que existe 
y actúa como esfera central de orientación valorativa del conjunto. Por lo cual, las instituciones hegemónicas de cada ámbito de existencia social son universales a la población del mundo como modelos intersubjetivos. Así, el Estado-nación, la familia burguesa, la empresa, la racionalidad eurocéntrica.

Por lo tanto, sea lo que sea lo que el término modernidad mienta, hoy involucra al conjunto de la población mundial y a toda su historia de los últimos 500 años, a todos los mundos o ex mundos articulados en el patrón global de poder, a cada uno de sus segmentos diferenciados o diferenciables, pues se constituyó junto con, como parte de, la redefinición o reconstitución histórica de cada uno de ellos por su incorporación al nuevo y común patrón de poder mundial. Por lo tanto, también como articulación de muchas racionalidades. En otros términos, puesto que se trata de una historia nueva y diferente, con experiencias específicas, las cuestiones que esta historia permite y obliga a abrir no pueden ser indagadas, mucho menos contestadas, con el concepto eurocéntrico de modernidad. Por lo mismo, decir que es un fenómeno puramente europeo o que ocurre en todas las culturas, tendría hoy un imposible sentido. Se trata de algo nuevo y diferente, específico de este pa- trón de poder mundial. Si hay que preservar el nombre, debe tratarse, de todos modos, de otra modernidad.

La cuestión central que nos interesa aquí es la siguiente: ¿qué es lo realmente nuevo respecto de la modernidad? ¿No solamente lo que desarrolla y redefine experiencias, tendencias y procesos de otros mundos, sino lo que fue producido en la historia propia del actual patrón de poder mundial?

Dussel ha propuesto la categoría de transmodernidad como alternativa a la pretensión eurocéntrica de que Europa es la productora original de la modernidad ${ }^{20}$. Según esa propuesta, la constitución del ego individual diferenciado es lo nuevo que ocurre con América y es la marca de la modernidad, pero tiene lugar no sólo en Europa sino en todo el mundo que se configura a partir de América. Dussel da en el blanco al recusar uno de los mitos predilectos del eurocentrismo. Pero no es seguro que el ego individual diferenciado sea un fenómeno exclusivamente perteneciente al período iniciado con América.

Hay, por supuesto, una relación umbilical entre los procesos históricos que se generan

20 Enrique Dussel (1995). 
a partir de América y los cambios de la subjetividad o, mejor dicho, de la intersubjetividad de todos los pueblos que se van integrando en el nuevo patrón de poder mundial. Y esos cambios llevan a la constitución de una nueva subjetividad, no sólo individual, sino colectiva, de una nueva intersubjetividad. Ese es, por lo tanto, un fenómeno nuevo que ingresa a la historia con América y en ese sentido hace parte de la modernidad. Pero cualesquiera que fuesen, esos cambios no se constituyen desde la subjetividad individual, ni colectiva, del mundo preexistente, vuelta sobre sí misma, o, para repetir la vieja imagen, esos cambios no nacen como Minerva de la cabeza de Zeus, sino que son la expresión subjetiva o intersubjetiva de lo que las gentes del mundo están haciendo en ese momento.

Desde esa perspectiva, es necesario admitir que América y sus consecuencias inmediatas en el mercado mundial y en la formación de un nuevo patrón de poder mundial, son un cambio histórico verdaderamente enorme y que no afecta solamente a Europa sino al conjunto del mundo. No se trata de cambios dentro del mundo conocido, que no alteran sino algunos de sus rasgos. Se trata del cambio del mundo como tal. Este es, sin duda, el elemento fundante de la nueva subjetividad: la percepción del cambio histórico. Es ese elemento lo que desencadena el proceso de constitución de una nueva perspectiva sobre el tiempo y sobre la historia. La percepción del cambio lleva a la idea del futuro, puesto que es el único territorio del tiempo donde pueden ocurrir los cambios. El futuro es un territorio temporal abierto. El tiempo puede ser nuevo, pues no es solamente la extensión del pasado. Y, de esa manera, la historia puede ser percibida ya no sólo como algo que ocurre, sea como algo natural o producido por decisiones divinas o misteriosas como el destino, sino como algo que puede ser producido por la acción de las gentes, por sus cálculos, sus intenciones, sus decisiones, por lo tanto como algo que puede ser proyectado, y, en consecuencia, tener sentido ${ }^{21}$.

Con América se inicia, pues, un entero universo de nuevas relaciones materiales e intersubjetivas. Es pertinente, por todo eso, admitir que el concepto de modernidad no se refiere solamente a lo que ocurre con la subjetividad, no obstante toda la tremenda importancia de ese proceso, sea que se trate de la emergencia del ego individual, o de un nuevo universo de relaciones intersubjetivas entre los individuos

21 Ver: "Modernidad, identidad y utopía en América Latina" (Quijano: 1988a). 
y entre los pueblos integrados o que se integran en el nuevo sistema-mundo y su específico patrón de poder mundial. El concepto de modernidad da cuenta, igualmente, de los cambios en la dimensión material de las relaciones sociales. Es decir, los cambios ocurren en todos los ámbitos de la existencia social de los pueblos $\mathrm{y}$, por tanto de sus miembros individuales, lo mismo en la dimensión material que en la dimensión subjetiva de esas relaciones. Y puesto que se trata de procesos que se inician con la constitución de América, de un nuevo patrón de poder mundial y de la integración de los pueblos de todo el mundo en ese proceso, de un entero y complejo sistema-mundo, es también imprescindible admitir que se trata de todo un período histórico. En otros términos, a partir de América un nuevo espacio / tiempo se constituye, material y subjetivamente: eso es lo que mienta el concepto de modernidad.

No obstante, fue decisivo para el proceso de modernidad que el centro hegemónico de ese mundo estuviera localizado en las zonas del centro y norte de Europa Occidental. Eso ayuda a explicar por qué el centro de elaboración intelectual de ese proceso se localizará también allí, y por qué esa versión fue la que ganó hegemonía mundial. Ayuda igualmente a explicar por qué la colonialidad del poder juga- rá un papel de primer orden en esa elaboración eurocéntrica de la modernidad. Esto último no es muy difícil de percibir si se tiene en cuenta lo que ya ha sido mostrado antes, el modo como la colonialidad del poder está vinculada a la concentración en Europa del capital, del salariado, del mercado del capital, en fin, de la sociedad y de la cultura asociadas a esas determinaciones. En ese sentido, la modernidad fue también colonial desde su punto de partida. Pero ayuda también a entender por qué fue en Europa mucho más directo e inmediato el impacto del proceso mundial de modernización.

En efecto, las nuevas prácticas sociales implicadas en el patrón de poder mundial, capitalista, la concentración del capital y del salariado, el nuevo mercado del capital, todo ello asociado a la nueva perspectiva sobre el tiempo y sobre la historia, a la centralidad de la cuestión del cambio histórico en dicha perspectiva, como experiencia y como idea, requieren, necesariamente, la des-sacralización de las jerarquías y de las autoridades, tanto en la dimensión material de las relaciones sociales como en su intersubjetividad; la des-sacralización, el cambio o el desmantelamiento de las correspondientes estructuras e instituciones. La individuación de las gentes sólo adquiere su sentido en ese contexto, la necesidad de 
un foro propio para pensar, para dudar, para decidir; la libertad individual, en suma, contra las adscripciones sociales fijadas y en consecuencia la necesidad de igualdad social entre los individuos.

Las determinaciones capitalistas, sin embargo, requerían también, y en el mismo movimiento histórico, que esos procesos sociales, materiales e intersubjetivos, no pudieran tener lugar sino dentro de relaciones sociales de explotación y de dominación. En consecuencia, como un campo de conflictos por la orientación, es decir, los fines, los medios y los límites de esos procesos. Para los controladores del poder, los controles del capital y del mercado eran, y son, los que deciden los fines, los medios y los límites del proceso. El mercado es el piso, pero también el límite de la posible igualdad social entre las gentes. Para los explotados del capital y en general para los dominados del patrón de poder, la modernidad generó un horizonte de liberación de las gentes de toda relación, estructura o institución vinculada a la dominación y a la explotación, pero también las condiciones sociales para avanzar en dirección a ese horizonte. La modernidad es, pues, también una cuestión de conflicto de intereses sociales. Uno de ellos es la continuada democratización de la existencia social de las gentes.
En ese sentido, todo concepto de modernidad es necesariamente ambiguo y contradictorio ${ }^{22}$.

Es allí, precisamente, donde la historia de esos procesos diferencia tan claramente a $\mathrm{Eu}$ ropa Occidental y el resto del mundo, para el caso, América Latina. En Europa Occidental, la concentración de la relación capital-salario es el eje principal de las tendencias de las relaciones de clasificación social y de la correspondiente estructura de poder. Eso subyace a los enfrentamientos con el antiguo orden, con el Imperio, con el Papado, durante el período del llamado capital competitivo. Esos enfrentamientos permiten, a los sectores no dominantes del capital y a los explotados, mejores condiciones de negociar su lugar en el poder y la venta de su fuerza de trabajo. De otro lado, abre también condiciones para una secularización específicamente burguesa de la cultura y de la subjetividad. El liberalismo es una de las claras expresiones de ese contexto material y subjetivo de la sociedad en Europa Occidental. En cambio, en el resto del mundo, en América Latina en particular, las formas más extendidas de control del trabajo son no-salariales,

22 Ver: "Estado-nación, ciudadanía y democracia: cuestiones abiertas" (Quijano, 1998). También "El fantasma del desarrollo" (Quijano, 2000a). 
aunque en beneficio global del capital, lo que implica que las relaciones de explotación y de dominación tienen carácter colonial. La Independencia política, desde comienzos del siglo XIX, está acompañada en la mayoría de los nuevos países por el estancamiento y retroceso del capital y fortalece el carácter colonial de la dominación social y política bajo Estados formalmente independientes. El eurocentramiento del capitalismo colonial / moderno, fue en ese sentido decisivo para el destino diferente del proceso de la modernidad entre Europa y el resto del mundo ${ }^{23}$.

\section{Colonialidad del poder Y EUROCENTRISMO}

La elaboración intelectual del proceso de modernidad produjo una perspectiva de conocimiento y un modo de producir conocimiento que dan muy ceñida cuenta del carácter del patrón mundial de poder: colonial / moderno, capitalista y eurocentrado. Esa perspectiva y

23 Ver: "Modernidad, identidad y utopía en América Latina” (Quijano: 1988a); "Colonialité du Pouvoir, Démocratie et Citoyenneté en Amérique Latine" (Quijano, 1994). modo concreto de producir conocimiento se reconocen como eurocentrismo ${ }^{24}$.

Eurocentrismo es, aquí, el nombre de una perspectiva de conocimiento cuya elaboración sistemática comenzó en Europa Occidental antes de mediados del siglo XVII, aunque algunas de sus raíces son sin duda más viejas, incluso antiguas, y que en las centurias siguientes se hizo mundialmente hegemónica recorriendo el mismo cauce del dominio de la Europa burguesa. Su constitución ocurrió asociada a la específica secularización burguesa del pensamiento europeo y a la experiencia y las necesidades del patrón mundial de poder capitalista, colonial / moderno, eurocentrado, establecido a partir de América.

No se trata, en consecuencia, de una categoría que implica a toda la historia cognoscitiva en toda Europa, ni en Europa Occidental en particular. En otros términos, no se refiere a todos los modos de conocer de todos los europeos y en todas las épocas, sino a una específica racionalidad o perspectiva de conocimiento que se hace mundialmente hegemónica colonizando

24 La literatura del debate sobre el eurocentrismo crece rápidamente. Una posición diferente de la que orienta este artículo, aunque emparentada, es la de Samir Amin (1989). 
y sobreponiéndose a todas las demás, previas o diferentes, y a sus respectivos saberes concretos, tanto en Europa como en el resto del mundo. En el marco de este trabajo lo que me propongo es discutir algunas de sus cuestiones más directamente vinculadas a la experiencia histórica de América Latina, pero que, obviamente, no se refieren solamente a ella.

\section{Capital y CAPitalismo}

Primero que nada, la teoría de una secuencia histórica unilineal y universalmente válida entre las formas conocidas de trabajo y de control del trabajo, que fueran también conceptualizadas como relaciones o modos de producción, especialmente entre capital y pre capital, precisa ser, en todo caso respecto de América, abierta de nuevo como cuestión mayor del debate científico-social contemporáneo.

Desde el punto de vista eurocéntrico, reciprocidad, esclavitud, servidumbre y producción mercantil independiente son todas percibidas como una secuencia histórica previa a la mercantilización de la fuerza de trabajo. Son pre capital. Y son consideradas no sólo como diferentes sino como radicalmente incompatibles con el capital. El hecho es, sin embargo, que en América ellas no emergieron en una secuencia histórica unilineal; ninguna de ellas fue una mera extensión de antiguas formas precapitalistas, ni fueron tampoco incompatibles con el capital.

En América la esclavitud fue deliberadamente establecida y organizada como mercancía para producir mercancías para el mercado mundial y, de ese modo, para servir a los propósitos y necesidades del capitalismo. Así mismo, la servidumbre fue impuesta sobre los indios, inclusive la redefinición de las instituciones de la reciprocidad, para servir los mismos fines, por ejemplo, para producir mercancías para el mercado mundial. Y en fin, la producción mercantil independiente fue establecida y expandida para los mismos propósitos.

Eso significa que todas esas formas de trabajo y de control del trabajo en América no sólo actuaban simultáneamente, sino que estuvieron articuladas alrededor del eje del capital y del mercado mundial. Consecuentemente, fueron parte de un nuevo patrón de organización y de control del trabajo en todas sus formas históricamente conocidas, juntas y alrededor del capital. Juntas configuraron un nuevo sistema: el capitalismo.

El capital, como relación social basada en la mercantilización de la fuerza de trabajo, nació probablemente en algún momento circa 
los siglos XI a XII, en algún lugar en la región meridional de las penínsulas ibérica y/o itálica y por consecuencia, y por conocidas razones, en el mundo islámico. Es pues bastante más antiguo que América. Pero antes de la emergencia de América, no está en ningún lugar estructuralmente articulado a todas las demás formas de organización y control de la fuerza de trabajo y del trabajo, ni tampoco era aún predominante sobre ninguna de ellas. Sólo con América pudo el capital consolidarse y obtener predominancia mundial, deviniendo precisamente en el eje alrededor del cual todas las demás formas fueron articuladas para los fines del mercado mundial. Sólo de ese modo, el capital se convirtió en el modo de producción dominante. Así, el capital existió mucho tiempo antes que América. Sin embargo, el capitalismo como sistema de relaciones de producción, esto es, el heterogéneo engranaje de todas las formas de control del trabajo y de sus productos bajo el dominio del capital, en que de allí en adelante consistió la economía mundial y su mercado, se constituyó en la historia sólo con la emergencia de América. A partir de ese momento, el capital siempre ha existido y continúa existiendo hoy en día sólo como el eje central del capitalismo, no de manera separada, mucho menos aislada. Nunca ha sido predominante de otro modo, a escala mundial y global, y con toda probabilidad no habría podido desarrollarse de otro modo.

\section{EVOLUCIONISMO Y DUALISMO}

Como en el caso de las relaciones entre capital y pre capital, una línea similar de ideas fue elaborada acerca de las relaciones entre Europa y no-Europa. Como ya fue señalado, el mito fundacional de la versión eurocéntrica de la modernidad es la idea del estado de naturaleza como punto de partida del curso civilizatorio cuya culminación es la civilización europea $u$ occidental. De ese mito se origina la específicamente eurocéntrica perspectiva evolucionista, de movimiento y de cambio unilineal y unidireccional de la historia humana. Dicho mito fue asociado con la clasificación racial de la población del mundo. Esa asociación produjo una visión en la cual se amalgaman, paradójicamente, evolucionismo y dualismo. Esa visión sólo adquiere sentido como expresión del exacerbado etnocentrismo de la recién constituida Europa, por su lugar central y dominante en el capitalismo mundial colonial / moderno, de la vigencia nueva de las ideas mitificadas de humanidad y de progreso, entrañables productos de la Ilustración, y en la vigencia de la idea de 
raza como criterio básico de clasificación social universal de la población del mundo.

La historia es, sin embargo, muy distinta. Por un lado, en el momento en que los ibéricos conquistaron, nombraron y colonizaron América (cuya región norte o Norte América, colonizarán los británicos un siglo más tarde), hallaron un gran número de diferentes pueblos, cada uno con su propia historia, lenguaje, descubrimientos y productos culturales, memoria e identidad. Son conocidos los nombres de los más desarrollados y sofisticados de ellos: aztecas, mayas, chimús, aymaras, incas, chibchas, etc. Trescientos años más tarde todos ellos quedaban reunidos en una sola identidad: indios. Esta nueva identidad era racial, colonial y negativa. Así también sucedió con las gentes traídas forzadamente desde la futura África como esclavas: ashantis, yorubas, zulús, congos, bacongos, etc. En el lapso de 300 años, todos ellos no eran ya sino negros.

Ese resultado de la historia del poder colonial tuvo dos implicaciones decisivas. La primera es obvia: todos aquellos pueblos fueron despojados de sus propias y singulares identidades históricas. La segunda es, quizás, menos obvia, pero no es menos decisiva: su nueva identidad racial, colonial y negativa, implicaba el despojo de su lugar en la historia de la producción cultural de la humanidad. En adelante no eran sino razas inferiores, capaces sólo de producir culturas inferiores. Implicaba también su reubicación en el nuevo tiempo histórico, constituido con América primero y con Europa después: en adelante eran el pasado. En otros términos, el patrón de poder fundado en la colonialidad implicaba también un patrón cognitivo, una nueva perspectiva de conocimiento dentro de la cual lo no-europeo era el pasado y de ese modo inferior, siempre primitivo.

Por otro lado, la primera identidad geocultural moderna y mundial fue América. Europa fue la segunda y fue constituida como consecuencia de América, no a la inversa. La constitución de Europa como nueva entidad / identidad histórica se hizo posible, en primer lugar, con el trabajo gratuito de los indios, negros y mestizos de América, con su avanzada tecnología en la minería y en la agricultura, y con sus respectivos productos, el oro, la plata, la papa, el tomate, el tabaco, etcétera, etcétera $^{25}$. Porque fue sobre esa base que se configuró una región como sede del control de las rutas atlánticas, a su vez convertidas,

25 Véase sobre este punto: Viola y Margolis (1991). 
precisamente sobre esa misma base, en las decisivas del mercado mundial. Esa región no tardó en emerger como Europa. América y Europa se produjeron históricamente, así, mutuamente, como las dos primeras nuevas identidades geoculturales del mundo moderno. Sin embargo, los europeos se persuadieron a sí mismos, desde mediados del siglo XVII, pero sobre todo durante el siglo XVIII, no sólo de que de algún modo se habían autoproducido a sí mismos como civilización, al margen de la historia iniciada con América, culminando una línea independiente que empezaba con Grecia como única fuente original. También concluyeron que eran naturalmente (por ejemplo, racialmente) superiores a todos los demás, puesto que habían conquistado a todos y les habían impuesto su dominio.

La confrontación entre la experiencia histórica y la perspectiva eurocéntrica de conocimiento permite señalar algunos de los elementos más importantes del eurocentrismo: a) una articulación peculiar entre un dualismo (pre capital-capital, no europeo-europeo, primitivocivilizado, tradicional-moderno, etc.) y un evolucionismo lineal, unidireccional, desde algún estado de naturaleza a la sociedad moderna europea; b) la naturalización de las diferencias culturales entre grupos humanos por medio de su codificación con la idea de raza; y c) la distorsionada reubicación temporal de todas esas diferencias, de modo que todo lo no-europeo es percibido como pasado. Todas estas operaciones intelectuales son claramente interdependientes. Y no habrían podido ser cultivadas y desarrolladas sin la colonialidad del poder.

\section{HOMOGENEIDAD / CONTINUIDAD Y HETEROGENEIDAD / DISCONTINUIDAD}

Como es observable ahora, la perspectiva eurocéntrica de conocimiento, debido a su radical crisis, es hoy un campo pletórico de cuestiones. Aquí es pertinente aún dejar planteadas dos de ellas. Primero, una idea del cambio histórico como un proceso o un momento en el cual una entidad o unidad se transforma de manera continua, homogénea y completa en otra cosa y abandona de manera absoluta la escena histórica. Esto le permite a otra entidad equivalente ocupar el lugar, y todo esto continúa en una cadena secuencial. De otro modo no tendría sentido, ni lugar, la idea de la historia como una evolución unidireccional y unilineal. Segundo, de allí se desprende que cada unidad diferenciada, por ejemplo una "economía / sociedad" o un "modo de producción" en el caso del control del trabajo (capital 
o esclavitud) o una "raza / civilización" en el caso de grupos humanos, es una entidad / identidad homogénea. Más aún, que son, cada una, estructuras de elementos homogéneos relacionados de manera continua y sistémica (lo que es distinto de sistemática).

La experiencia histórica demuestra sin embargo que el capitalismo mundial está lejos de ser una totalidad homogénea y continua. Al contrario, como lo demuestra América, el patrón de poder mundial que se conoce como capitalismo es, en lo fundamental, una estructura de elementos heterogéneos, tanto en términos de las formas de control del trabajo-recursosproductos (o relaciones de producción) o en términos de los pueblos e historias articulados en él. En consecuencia, tales elementos se relacionan entre sí y con el conjunto de manera también heterogénea y discontinua, incluso conflictiva. Y son ellos mismos, cada uno, configurados del mismo modo.

Así, cada una de esas relaciones de producción es en sí misma una estructura heterogénea. Especialmente el capital, desde que todos los estadios y formas históricas de producción de valor y de apropiación de plusvalor (por ejemplo: acumulación primitiva, plusvalía absoluta y relativa, extensiva o intensiva; o en otra nomenclatura: manufactura, capital competitivo, capital monopólico, capital transnacional o global, o pre fordista, fordista, de mano de obra intensiva, de capital intensivo, de información intensiva, etc., etc.) están simultáneamente en actividad y trabajan juntos en una compleja malla de transferencia de valor y de plusvalor. Esto es igualmente cierto respecto de las razas, ya que tantos pueblos diversos y heterogéneos, con heterogéneas historias y tendencias históricas de movimiento y de cambio fueron reunidos bajo un solo membrete racial, por ejemplo indio o negro.

Esta heterogeneidad no es simplemente estructural, basada en las relaciones entre elementos coetáneos. Ya que historias diversas y heterogéneas de este tipo fueron articuladas en una sola estructura de poder, es pertinente admitir el carácter histórico-estructural de esa heterogeneidad.

Consecuentemente, el proceso de cambio de dicha totalidad capitalista no puede, de ningún modo, ser una transformación homogénea y continua del sistema entero, ni tampoco de cada uno de sus componentes mayores. Tampoco podría dicha totalidad desvanecerse completa y homogéneamente de la escena histórica y ser reemplazada por otra equivalente. El cambio histórico no puede ser unilineal, unidireccional, secuencial o total. El sistema, 
o el específico patrón de articulación estructural, podría ser desmantelado. Pero aún así cada uno o algunos de sus elementos puede y habrá de rearticularse en algún otro patrón estructural, como ocurrió, obviamente, con los componentes del patrón de poder pre colonial en, digamos, el Tawantinsuyu ${ }^{26}$.

\section{EL NUEVO DUALISMO}

Finalmente, por el momento y para nuestros propósitos aquí, es pertinente abrir la cuestión de las relaciones entre el cuerpo y el no-cuerpo en la perspectiva eurocéntrica, tanto por su gravitación en el modo eurocéntrico de producir conocimiento, como debido a que en nuestra experiencia tiene una estrecha relación con las de raza y género.

La idea de la diferenciación entre el "cuerpo" y el "no-cuerpo" en la experiencia humana es virtualmente universal a la historia de la hu-

26 Sobre el origen de la categoría de heterogeneidad histórico-estructural véase: "Notas sobre el concepto de marginalidad social" (Quijano, 1966); incorporado después al volumen Imperialismo y marginalidad en América Latina (Quijano, 1977). Puede verse, también: "La nueva heterogeneidad estructural de América Latina" (Quijano, 1988). manidad, común a todas las "culturas" o "civilizaciones" históricamente conocidas. Pero es también común a todas -hasta la aparición del eurocentrismo- la permanente co-presencia de los dos elementos como dos dimensiones no separables del ser humano, en cualquier aspecto, instancia o comportamiento.

El proceso de separación de estos elementos del ser humano es parte de una larga historia del mundo cristiano sobre la base de la idea de la primacía del "alma" sobre el "cuerpo". Pero esta historia muestra también una larga e irresuelta ambivalencia de la teología cristiana sobre este punto en particular. Ciertamente, es el "alma" el objeto privilegiado de salvación. Pero al final, es el "cuerpo" el resurrecto, como culminación de la salvación.

Ciertamente, también, fue durante la cultura represiva del cristianismo, como resultado de los conflictos con musulmanes y judíos, sobre todo entre los siglos XV y XVI en plena Inquisición, que la primacía del "alma" fue enfatizada, quizás exasperada. Y porque el "cuerpo" fue el objeto básico de la represión, el "alma" pudo aparecer casi separada de las relaciones intersubjetivas al interior del mundo cristiano. Pero esto no fue teorizado, es decir, sistemáticamente discutido y elaborado, hasta Descartes, culminando el proceso 
de la secularización burguesa del pensamiento cristiano ${ }^{27}$.

Con Descartes ${ }^{28}$ lo que sucede es la mutación del antiguo abordaje dualista sobre el "cuerpo" y el "no-cuerpo". Lo que era una co-presencia permanente de ambos elementos en cada etapa del ser humano, en Descartes se convierte en una radical separación entre "razón / sujeto" y "cuerpo". La razón no es solamente una secularización de la idea de "alma" en el sentido teológico, sino que es una mutación en una nueva id-entidad, la "razón / sujeto", la única entidad capaz de conocimiento "racional", respecto del cual el "cuerpo" es y no puede ser otra cosa que "objeto" de conocimiento. Desde

27 Siempre me he preguntado por el origen de una de las más caras propuestas del Liberalismo: las ideas deben ser respetadas. El cuerpo, en cambio, puede ser torturado, triturado y muerto. Los latinoamericanos solemos citar con admiración la desafiante frase de un mártir de las luchas anticoloniales, en el momento mismo de ser degollado: “iBárbaros, las ideas no se degüellan!”. Sugiero ahora que su origen debe buscarse en ese nuevo dualismo cartesiano, que convirtió al "cuerpo" en mera "naturaleza".

28 Cf. Discours de la méthode (varias ediciones). También "Méditations" y "Description du corps humain" (1967). Paul Bousquié (1994) acierta en este punto: el cartesianismo es un nuevo dualismo radical. ese punto de vista el ser humano es, por excelencia, un ser dotado de "razón", y ese don se concibe como localizado exclusivamente en el alma. Así el "cuerpo", por definición incapaz de razonar, no tiene nada que ver con la "razón / sujeto". Producida esa separación radical entre "razón / sujeto" y "cuerpo", las relaciones entre ambos deben ser vistas únicamente como relaciones entre la "razón / sujeto" humana y el "cuerpo / naturaleza" humana, o entre "espíritu" y "naturaleza". De este modo, en la racionalidad eurocéntrica el "cuerpo" fue fijado como "objeto" de conocimiento, fuera del entorno del "sujeto / razón".

Sin esa "objetivización" del "cuerpo" como "naturaleza”, de su expulsión del ámbito del "espíritu", difícilmente hubiera sido posible intentar la teorización "científica" del problema de la raza, como fue el caso del Conde de Gobineau durante el siglo XIX ${ }^{29}$. Desde esa perspectiva eurocéntrica, ciertas razas son condenadas como "inferiores" por no ser sujetos "racionales". Son objetos de estudio, "cuerpo" en consecuencia, más próximos a la "naturaleza". En un sentido, esto los convierte en dominables y explotables. De acuerdo

29 Essais sur l'inégalité des races humaines (París: s/d, 1853-1857). 
al mito del estado de naturaleza y de la cadena del proceso civilizatorio que culmina en la civilización europea, algunas razas -negros (o africanos), indios, oliváceos, amarillos (o asiáticos) y en esa secuencia- están más próximas a la "naturaleza" que los blancos ${ }^{30}$. Sólo desde esa peculiar perspectiva fue posible que los pueblos no-europeos fueran considerados, virtualmente hasta la Segunda Guerra Mundial, ante todo como objeto de conocimiento y de dominación / explotación por los europeos.

Ese nuevo y radical dualismo no afectó solamente a las relaciones raciales de dominación, sino también a las más antiguas, las relaciones sexuales de dominación. En adelante, el lugar de las mujeres, muy en especial el de las mujeres de las razas inferiores, quedó estereotipado junto con el resto de los cuerpos, y tanto más inferiores fueran sus razas, tanto más cerca de la naturaleza o directamente, como en el caso de las esclavas negras, dentro

30 Acerca de esos procesos en la subjetividad eurocentrada, dice mucho el que la única categoría alterna a Occidente era, y aún lo es, Oriente, mientras que los negros (África) o los indios (América antes de los Estados Unidos) no tenían el honor de ser el Otro de Europa u Occidente. de la naturaleza. Es probable, aunque la cuestión queda por indagar, que la idea de género se haya elaborado después del nuevo y radical dualismo como parte de la perspectiva cognitiva eurocentrista.

Durante el siglo XVIII, ese nuevo dualismo radical fue amalgamado con las ideas mitificadas de "progreso" y de un estado de naturaleza en la trayectoria humana, los mitos fundacionales de la versión eurocentrista de la modernidad. Esto dio pie a la peculiar perspectiva histórica dualista / evolucionista. Así todos los no-europeos pudieron ser considerados, de un lado, como pre europeos y al mismo tiempo dispuestos en cierta cadena histórica y continua desde lo primitivo a lo civilizado, de lo irracional a lo racional, de lo tradicional a lo moderno, de lo mágico-mítico a lo científico. En otras palabras, desde lo no-europeo / pre europeo a algo que en el tiempo se europeizará o "modernizará".

Sin considerar la experiencia entera del colonialismo y de la colonialidad esa marca intelectual sería difícilmente explicable, así como la duradera hegemonía mundial del eurocentrismo. Las solas necesidades del capital como tal, no agotan, no podrían agotar, la explicación del carácter y de la trayectoria de esa perspectiva de conocimiento. 


\section{EUROCENTRISMO Y EXPERIENCIA HISTÓRICA EN AMÉRICA LATINA}

Aplicada de manera específica a la experiencia histórica latinoamericana, la perspectiva eurocéntrica de conocimiento opera como un espejo que distorsiona lo que refleja. Es decir, la imagen que encontramos en ese espejo no es del todo quimérica, ya que poseemos tantos y tan importantes rasgos históricos europeos en tantos aspectos, materiales e intersubjetivos. Pero, al mismo tiempo, somos tan profundamente distintos. De ahí que cuando miramos a nuestro espejo eurocéntrico, la imagen que vemos sea necesariamente parcial y distorsionada.

Aquí la tragedia es que todos hemos sido conducidos, sabiéndolo o no, queriéndolo o no, a ver y aceptar aquella imagen como nuestra y como perteneciente a nosotros solamente. De esa manera seguimos siendo lo que no somos. Y como resultado no podemos nunca identificar nuestros verdaderos problemas, mucho menos resolverlos, a no ser de una manera parcial y distorsionada.

\section{EL EUROCENTRISMO Y LA “CUESTIÓN NACIONAL": EL ESTADO-NACIÓN}

Uno de los ejemplos más claros de esta tragedia de equivocaciones en América Latina es la historia de la llamada cuestión nacional. Dicho de otro modo, del problema del moderno Estado-nación en América Latina.

Naciones y Estados son un viejo fenómeno. Sin embargo, aquello que llamamos el moderno Estado-nación es una experiencia muy específica. Se trata de una sociedad nacionalizada y por eso políticamente organizada como un Estado-nación. Implica a las instituciones modernas de ciudadanía y democracia política. Es decir, implica una cierta democracia, dado que cada proceso conocido de nacionalización societal en los tiempos modernos ha ocurrido solamente a través de una relativa (o sea, dentro de los límites del capitalismo) pero importante y real democratización del control del trabajo, de los recursos productivos y del control de la generación y gestión de las instituciones políticas. De este modo, la ciudadanía puede llegar a servir como igualdad legal, civil y política para gentes socialmente desiguales ${ }^{31}$.

Un Estado-nación es una suerte de sociedad individualizada entre las demás. Por eso, entre sus miembros puede ser sentida como identidad. Sin embargo, toda sociedad es una estructura de poder. Es el poder aquello que

31 Sobre este punto véase mi "Estado-nación, ciudadanía y democracia: cuestiones abiertas” (Quijano, 1998). 
articula formas de existencia social dispersas y diversas en una totalidad única, una sociedad. Toda estructura de poder es siempre, parcial o totalmente, la imposición de algunos, a menudo cierto grupo, sobre los demás. Consecuentemente, todo Estado-nación posible es una estructura de poder, del mismo modo en que es producto del poder. En otros términos, del modo en que han quedado configuradas las disputas por el control del trabajo, sus recursos y productos; del sexo, sus recursos y productos; de la autoridad y de su específica violencia; de la intersubjetividad y del conocimiento.

No obstante, si un Estado-nación moderno puede expresarse en sus miembros como una identidad, no es solamente debido a que puede ser imaginado como una comunidad ${ }^{32}$. Los miembros precisan tener en común algo real, no sólo imaginado, algo que compartir. $\mathrm{Y}$ eso, en todos los reales Estados-nación modernos, es una participación más o menos democrática en la distribución del control del poder. Esta es la manera específica de

32 Como sugiere Benedict Anderson (1991) en Imagined Communities. Una discusión más extensa sobre este punto en mi "Estado-nación, ciudadanía y democracia: cuestiones abiertas” (Quijano, 1998). homogeneización de la gente en un Estadonación moderno. Toda homogeneización de la población de un Estado-nación moderno, es desde luego parcial y temporal y consiste en la común participación democrática en el control de la generación y de la gestión de las instituciones de autoridad pública y de sus específicos mecanismos de violencia. Esto es, se ejerce, en lo fundamental, en todo el ámbito de la existencia social vinculado al Estado y que por ello se asume como lo explícitamente político. Pero dicho ámbito no podría ser democrático, esto es, implicar ciudadanía como igualdad jurídica y civil de gentes desigualmente ubicadas en las relaciones de poder, si las relaciones sociales en todos los otros ámbitos de la existencia social fueran radicalmente no democráticas o antidemocráticas ${ }^{33}$.

Puesto que todo Estado-nación es una estructura de poder, eso implica que se trata de un poder que se configura en ese sentido. El

33 Una discusión más amplia sobre los límites y las condiciones de la democracia en una estructura de poder capitalista, en mi "El fantasma del desarrollo en América Latina" (Quijano, 2000a) y en "Estado-nación, ciudadanía y democracia: cuestiones abiertas” (Quijano, 1998). 
proceso empieza siempre con un poder político central sobre un territorio y su población, porque cualquier proceso de nacionalización posible sólo puede ocurrir en un espacio dado, a lo largo de un prolongado período de tiempo. Dicho espacio precisa ser más o menos estable por un largo período. En consecuencia, se precisa de un poder político estable y centralizado. Este espacio es, en ese sentido, necesariamente un espacio de dominación disputado $\mathrm{y}$ ganado frente a otros rivales.

En Europa, el proceso que llevó a la formación de estructuras de poder configuradas como Estados-nación, empezó con la emergencia de algunos pocos núcleos políticos que conquistaron su espacio de dominación y se impusieron sobre los diversos y heterogéneos pueblos e identidades que lo habitaban. De este modo el Estado-nación empezó como un proceso de colonización de algunos pueblos sobre otros que, en ese sentido, eran pueblos extranjeros. En algunos casos particulares, como en la España que se constituía sobre la base de América y sus ingentes y gratuitos recursos, el proceso incluyó la expulsión de algunos grupos, como los musulmanes y judíos, considerados como extranjeros indeseables. Esta fue la primera experiencia de limpieza étnica en el período moderno, seguida por la imposición de esa peculiar institución llamada "certificado de limpieza de sangre" ${ }^{34}$.

Por otro lado, el proceso de centralización estatal que antecedió en Europa Occidental a la formación de Estados-nación, fue paralelo a la imposición de la dominación colonial que comenzó con América. Es decir, simultáneamente con la formación de los imperios coloniales de esos primeros Estados centrales europeos. El proceso tiene, pues, un doble movimiento histórico. Comenzó como una colonización interna de pueblos con identidades diferentes, pero que habitaban los mismos territorios convertidos en espacios de dominación interna, es decir, en los mismos territorios de los futuros Estados-nación. Y siguió paralelamente a la colonización imperial o externa de pueblos que no sólo tenían identidades diferentes a las de los colonizadores, sino que habitaban territorios que no eran considerados como los espacios de dominación interna de los colonizadores, es decir no eran los mismos territorios de los futuros Estados-nación de los colonizadores.

34 Probablemente el antecedente más cercano de la idea de raza producida por los castellanos en América. Véase mi “'Raza', 'etnia' y 'nación' en Mariátegui: cuestiones abiertas” (Quijano, 1992a). 
Si indagamos desde nuestra actual perspectiva histórica aquello que sucedió con los primeros Estados centrales europeos, sus espacios de dominación (poblaciones y territorios) y sus respectivos procesos de nacionalización, se observa que las diferencias son muy visibles. La existencia de un fuerte Estado central no es suficiente para producir un proceso de relativa homogeneización de una población previamente diversa y heterogénea, para producir, así, una identidad común y una fuerte y duradera lealtad a dicha identidad. Entre esos casos, Francia es probablemente la más lograda experiencia, así como España es la menos exitosa.

¿Por qué Francia sí y España no? España era en sus inicios mucho más rica y poderosa que sus pares. Sin embargo, luego de la expulsión de los musulmanes y judíos dejó de ser productiva y próspera para convertirse en correa de trasmisión de los recursos de América a los centros emergentes del capital financiero mercantil. Al mismo tiempo, luego del violento y exitoso ataque en contra de la autonomía de las comunidades campesinas y de las ciudades y burgos, quedó atrapada en una estructura señorial de poder, y bajo la autoridad de una monarquía y de una iglesia represivas y corruptas. La monarquía de España se dedicó, además, a una política bélica en busca de la expansión de su poder señorial en Europa, en lugar de una hegemonía sobre el mercado mundial y el capital comercial y financiero, como hicieran luego Inglaterra o Francia. Todas las luchas por forzar a los controladores del poder a admitir o negociar alguna democratización de la sociedad y del Estado fueron derrotadas, notablemente la Revolución liberal de 1810-12. De este modo, el colonialismo interno y los patrones señoriales de poder político y social, combinados, demostraron ser fatales para la nacionalización de la sociedad y el Estado españoles, en la medida en que ese tipo de poder no sólo probó ser incapaz de sostener cualquier ventaja proveniente de ese rico y vasto colonialismo imperial o externo: probó igualmente que era muy poderosa valla a todo proceso democratizador de las relaciones sociales y políticas, y no sólo dentro del espacio propio de dominación.

Por el contrario, en Francia, a través de la democratización radical de las relaciones sociales y políticas con la Revolución francesa, el previo colonialismo interno evolucionó hacia una "francesización" efectivo, aunque no total, de los pueblos que habitaban el territorio de Francia, originalmente tan diversos e histórico-estructuralmente heterogéneos como en el espacio de dominación que se llamaría España. Los vascos franceses, por ejemplo son, en pri- 
mer lugar, franceses, como los occitanos o los navarros. No así en España.

En cada uno de los casos de exitosa nacionalización de sociedades y Estados en Europa, la experiencia es la misma: un importante proceso de democratización de la sociedad es la condición básica para la nacionalización de esa sociedad y de su organización política en un Estado-nación moderno. No hay, en verdad, excepción conocida a esa trayectoria histórica del proceso que conduce a la formación del Estado-nación.

\section{EL ESTADO-NACIón EN AMÉRICA: ESTADOS UNIDOS}

Si examinamos la experiencia de América, sea en sus áreas hispánica o británica, podemos reconocer diferencias y factores básicos equivalentes. En el área britano-americana, la ocupación del territorio fue desde el comienzo violenta. Pero antes de la Independencia, conocida en Estados Unidos como la Revolución americana, el territorio ocupado era muy pequeño. Por eso los indios no fueron habitantes del territorio ocupado, no estaban colonizados. Por eso, los diversos pueblos indios fueron formalmente reconocidos como naciones y con ellos se practicó relaciones comerciales inter-naciones, inclusive se formaron alianzas militares en las guerras entre colonialistas ingleses y franceses, sobre todo. Los indios no eran parte de la población incorporada al espacio de dominación colonial britano-americana. Por eso mismo, cuando se inicia la historia del nuevo Estado-nación llamado Estados Unidos de América del Norte, los indios fueron excluidos de esa nueva sociedad. Fueron considerados extranjeros. Pero, más adelante, sus tierras fueron conquistadas y ellos casi exterminados. Sólo entonces los sobrevivientes fueron encerrados en la sociedad norteamericana como raza colonizada. En el comienzo, pues, relaciones colonial / raciales existieron solamente entre blancos y negros. Este último grupo era fundamental para la economía de la sociedad colonial, como durante un primer largo momento para la economía de la nueva nación. Sin embargo, demográficamente los negros eran una relativamente reducida minoría, mientras que los blancos componían la gran mayoría.

Al fundarse Estados Unidos como país independiente, el proceso de constitución del nuevo patrón de poder llevó desde el comienzo a la configuración de un Estado-nación. En primer término, a pesar de la relación colonial de dominación entre blancos y negros y del exterminio colonialista de la población india, dada 
la condición abrumadoramente mayoritaria de los blancos, es inevitable admitir que dicho nuevo Estado-nación era genuinamente representativo de la mayoría de la población. Esa blanquitud social de la sociedad norteamericana fue incluso más lejos con la inmigración de millones de europeos durante el siglo XIX. En segundo término, la conquista de los territorios indios resultó en la abundancia de la oferta de un recurso básico de producción, la tierra. Este pudo ser, por consecuencia, apropiado y distribuido de manera no únicamente concentrada bajo el control de muy pocas gentes, sino por el contrario pudo ser, al mismo tiempo, parcialmente concentrado en grandes latifundios y también apropiado o distribuido en una vasta proporción de mediana y pequeña propiedad. Equivalente, pues, a una distribución democrática del recurso. Eso fundó para los blancos una participación notablemente democrática en el control de la generación y la gestión de la autoridad pública. La colonialidad del nuevo patrón de poder no fue anulada, sin embargo, ya que negros e indios no podían tener lugar, en absoluto, en el control de los recursos de producción, ni de las instituciones y mecanismos de la autoridad pública.
Hacia mediados del siglo XIX, Tocqueville ${ }^{35}$ observó que en Estados Unidos de América, gente de orígenes tan diversos cultural, étnica e incluso nacionalmente eran incorporados todos en algo parecido a una máquina de re-identificación nacional: rápidamente se convertían en ciudadanos estadounidenses y adquirían una nueva identidad nacional, incluso preservando por algún tiempo sus identidades originales. Tocqueville encontró que el mecanismo básico de ese proceso de nacionalización era la apertura de la participación democrática en la vida política para todos los recién llegados. Todos ellos eran atraídos hacia una intensa participación política y con la libertad de decisión de participar o no. Pero vio también que dos grupos específicos no estaban autorizados a participar en la vida política. Estos eran, evidentemente, negros e indios. Esa discriminación era, pues, el límite de ese impresionante y masivo proceso de formación del Estado-nación moderno en la joven república de Estados Unidos de América. Tocqueville no dejó de advertir que a menos que esa discriminación social y política fuera eliminada, el proceso de construcción nacional se vería limitado. Un siglo más tarde, otro eu-

35 Democracy in America (ediciones varias, 1835: Vol. 1, Caps., XVI y XVII). 
ropeo, Gunnar Myrdall ${ }^{36}$, observó esas mismas limitaciones en el proceso nacional de Estados Unidos. Vio también que debido a que los nuevos inmigrantes eran no-blancos (provenían de América Latina y de Asia, en su mayoría), las relaciones coloniales de los blancos con esos otros pueblos podrían ser un serio riesgo para la reproducción de esa nación. Sin duda esos riesgos van en aumento hoy en día, a medida en que el viejo mito del melting pot ha sido abandonado forzosamente y el racismo tiende a ser de nuevo agudo y violento.

En suma, la colonialidad de las relaciones de dominación / explotación / conflicto entre blancos y no-blancos, no obstante su intensa vigencia, dada la condición vastamente mayoritaria de los primeros no fue tan fuerte como para impedir la relativa, pero real e importante, democratización del control de recursos de producción y del Estado, entre blancos, es verdad, pero con el vigor necesario para que pudiera ser reclamada más tarde también por los no-blancos. El poder pudo ser configurado en la trayectoria y la orientación de un Estadonación. Es a eso que se refiere, sin duda, la idea de la Revolución americana.

36 American Dilemma (Myrdall, 1944).

\section{América Latina: Cono Sur Y MAYORÍA BLANCA}

A primera vista, la situación en los países del llamado Cono Sur de América Latina (Argentina, Chile y Uruguay) fue similar a la ocurrida en Estados Unidos. Los indios, en su mayoría, tampoco fueron integrados a la sociedad colonial, en la medida en que eran pueblos de más o menos la misma estructura que aquellos de Norteamérica, sin disponibilidad para convertirse en trabajadores explotados, no condenables a trabajar forzosamente y de manera disciplinada para los colonos. En esos tres países, también la población negra fue una minoría durante el período colonial, en comparación con otras regiones dominadas por españoles o portugueses. Y los dominantes de los nuevos países del Cono Sur consideraron, como en el caso de los Estados Unidos, necesaria la conquista del territorio que los indios poblaban y el exterminio de éstos como forma expeditiva de homogenizar la población nacional y de ese modo facilitar el proceso de constitución de un Estado-nación moderno, a la europea. En Argentina y Uruguay eso fue hecho en el siglo XIX. Y en Chile durante las tres primeras décadas del siglo XX. Estos países atrajeron también millones de inmigrantes europeos, con- 
solidando en apariencia la blanquitud de las sociedades de Argentina, Chile y Uruguay. En un sentido, esto también consolidó en apariencia el proceso de homogeneización en dichos países.

Un elemento crucial introdujo, sin embargo, una diferencia básica en esos países en comparación con el caso norteamericano, muy en especial en Argentina. Mientras en Estados Unidos la distribución de la tierra se produjo de una manera menos concentrada durante un importante período, en Argentina la apropiación de la tierra ocurrió de una manera completamente distinta. La extrema concentración de la tenencia de la tierra, en particular de las tierras conquistadas a los indios, hizo imposible cualquier tipo de relaciones sociales democráticas entre los propios blancos y, en consecuencia, de toda relación política democrática. Sobre esa base, en lugar de una sociedad democrática, capaz de representarse y organizarse políticamente en un Estado democrático, lo que se constituyó fue una sociedad y un Estado oligárquicos, sólo parcialmente desmantelados desde la Segunda Guerra Mundial. Sin duda, esas determinaciones se asociaron al hecho de que la sociedad colonial en ese territorio, sobre todo en la costa atlántica que devino hegemónica sobre el resto, fue poco desarrollada y por eso su reconocimiento como sede de un Virreinato fue tardío (segunda mitad del siglo XVIII). Su emergencia como una de las áreas prósperas del mercado mundial fue rápida desde el último cuarto del siglo XVIII, lo que impulsó en el siglo siguiente una masiva migración desde Europa del Sur, del Centro y del Este. Pero esa vasta población migratoria no encontró una sociedad con estructura, historia e identidad suficientemente densas y estables, para incorporarse a ella e identificarse con ella, como ocurrió en el caso de Estados Unidos y, sin duda, en Chile y Uruguay. A fines del XIX la población de Buenos Aires estaba formada en más de un $80 \%$ por migrantes de origen europeo. Tardaron, por eso probablemente, en considerarse con identidad nacional y cultural propias diferentes de la europea, mientras rechazaban explícitamente la identidad asociada a la herencia histórica latinoamericana y, en particular, cualquier parentesco con la población india ${ }^{37}$.

37 Todavía en los años veinte en pleno siglo XX, H. Murena, un miembro importante de la inteligencia argentina, no dudaba en proclamar: "somos europeos exilados en estas salvajes pampas". Ver Nosotros mañana (Imaz, 1964). Y tan tarde como en los años sesenta, en las luchas sociales, culturales y políticas de Argentina, 
La concentración de la tierra fue igualmente fuerte en Chile y algo menor en Uruguay. De todos modos, a diferencia de Argentina, los migrantes europeos encontraron en esos países una sociedad, un Estado, una identidad, ya suficientemente densos y constituidos, a los cuales incorporarse y con los cuales identificarse más pronto y más completamente que en el otro caso. En el caso de Chile, por otra parte, la expansión territorial a costa de Bolivia y de Perú, permitió a la burguesía chilena el control de recursos cuya importancia ha marcado desde entonces la historia del país: salitre primero, y cobre poco después. En las pampas salitreras se formó el primer gran contingente de asalariados obreros de América Latina, desde mediados del siglo XIX, y más tarde fue en el cobre que se formó la columna vertebral de las organizaciones sociales y políticas de los obreros chilenos de la vieja república. Los beneficios, distribuidos entre la burguesía británica y la chilena, permitieron el impulso de la agricultura comercial y de la economía comercial urbana. Se formaron nuevas capas de asalariados urbanos y nuevas capas medias relativamente amplias, junto con la modernización de una

"cabecita negra" era el despectivo mote de la discriminación específicamente racial. parte importante de la burguesía señorial. Fueron esas condiciones las que hicieron posible que los trabajadores y las capas medias pudieran negociar con algún éxito, desde 1930-35, las condiciones de la dominación / explotación / conflicto. Esto es, de la democracia en las condiciones del capitalismo. De ese modo, pudo ser establecido un poder configurado como Estado-nación de blancos, por supuesto. Los indios, exigua minoría de sobrevivientes habitando las tierras más pobres e inhóspitas del país, fueron excluidos de ese Estado-nación. Hasta hace poco eran sociológicamente invisibles. Ahora no lo son tanto, comienzan a movilizarse en defensa de esas mismas tierras que también arriesgan perder frente al capital global.

El proceso de homogeneización de los miembros de la sociedad imaginada desde una perspectiva eurocéntrica, como característica y condición de los Estados-nación modernos, fue llevado a cabo en los países del Cono Sur latinoamericano no por medio de la descolonización de las relaciones sociales y políticas entre los diversos componentes de la población, sino por la eliminación masiva de unos de ellos (indios, negros y mestizos). Es decir, no por medio de la democratización fundamental de las relaciones sociales y políticas, sino por la exclusión de una parte de la población. Dadas 
esas condiciones originales, la democracia alcanzada y el Estado-nación constituido, no podían ser afirmados y estables. La historia política de esos países, muy especial desde fines de los sesenta hasta hoy, no podría ser explicada al margen de esas determinaciones ${ }^{38}$.

\section{MAYORÍA INDIA, NEGRA Y MESTIZA: EL IMPOSIBLE “MODERNO ESTADO-NACIÓN”}

En el resto de países latinoamericanos, esa trayectoria eurocéntrica hacia el Estado-nación

38 La homogeneización es un elemento básico de la perspectiva eurocentrista de la nacionalización. Si así no fuera, no se podría explicar, ni entender, los conflictos nacionales en los países europeos cada vez que se plantea el problema de las diferencias racial-étnicas dentro de la población. No se podría entender tampoco, de otro modo, la política eurocéntrica de poblamiento favorecida por los liberales del Cono Sur de América Latina, ni el origen y el sentido del así llamado "problema indígena" en toda América Latina. Si los hacendados peruanos del siglo XIX importaron culíes chinos, fue, precisamente, porque la cuestión nacional no estaba en juego para ellos, sino el desnudo interés social. Ha sido por esa perspectiva eurocentrista, fundada en la colonialidad del poder, que la burguesía señorial latinoamericana ha sido enemiga de la democratización social y política, como condición de nacionalización de la sociedad y del Estado. se ha demostrado hasta ahora imposible de culminar. Tras la derrota de Tupac Amaru y de Haití, sólo en los casos de México y de Bolivia se llegó tan lejos como se pudo en el camino de la descolonización social, a través de un proceso revolucionario más o menos radical, durante el cual la descolonización del poder pudo recorrer un trecho importante antes de ser contenida y derrotada. En esos países, al comenzar la Independencia, principalmente aquellos que fueron demográfica y territorialmente extensos a principios del siglo XIX, aproximadamente poco más del $90 \%$ del total de la población estaba compuesta de negros, indios y mestizos. Sin embargo, en todos estos países, durante el proceso de organización de los nuevos Estados, a dichas razas les fue negada toda posible participación en las decisiones sobre la organización social y política. La pequeña minoría blanca que asumió el control de esos Estados se encontró inclusive con la ventaja de estar libre de las restricciones de la legislación de la Corona española, que se dirigían formalmente a la protección de las razas colonizadas. A partir de ahí llegaron inclusive a imponer nuevos tributos coloniales sobre los indios, sin perjuicio de mantener la esclavitud de los negros por muchas décadas. Por supuesto, esta minoría dominante se hallaba ahora en libertad para 
expandir su propiedad de la tierra a expensas de los territorios reservados para los indios por la reglamentación de la Corona española. En el caso del Brasil, los negros no eran sino esclavos y la mayoría de indios estaba constituida por pueblos de la Amazonía, siendo de esta manera extranjeros para el nuevo Estado.

Haití fue un caso excepcional donde se produjo, en el mismo movimiento histórico, una revolución nacional, social y racial. Es decir, una descolonización real y global del poder. $\mathrm{Su}$ derrota se produjo por las repetidas intervenciones militares por parte de los Estados Unidos. El otro proceso nacional en América Latina, en el Virreinato del Perú, liderado por Tupac Amaru II en 1780, fue tempranamente derrotado. Desde entonces, en todas las demás colonias ibéricas los grupos dominantes tuvieron éxito en tratar precisamente de evitar la descolonización de la sociedad mientras peleaban por tener Estados independientes.

Tales nuevos Estados no podrían ser considerados en modo alguno como nacionales, salvo que se admita que esa exigua minoría de colonizadores en el control fuera genuinamente representante del conjunto de la población colonizada. Las respectivas sociedades, fundadas en la dominación colonial de indios, negros y mestizos, no podrían tampoco ser considera- das nacionales, y ciertamente mucho menos, democráticas. Esto presenta una situación en apariencia paradójica: Estados independientes y sociedades coloniales ${ }^{39}$. La paradoja es sólo parcial o superficial; sin embargo, cuando observamos con más cuidado los intereses sociales de los grupos dominantes de aquellas sociedades coloniales y sus Estados independientes.

En la sociedad colonial britano-americana, ya que los indios constituían un pueblo extranjero, viviendo más allá de los confines de la sociedad colonial, la servidumbre no estuvo tan extendida como en la sociedad colonial de la América ibérica. Los sirvientes (indentured servants) traídos de la Gran Bretaña no eran legalmente siervos, y luego de la Independen-

39 En los sesenta y setenta muchos científicos sociales dentro y fuera de América Latina, entre los que me incluyo, usamos el concepto de "colonialismo interno" para caracterizar la aparente relación paradójica de los Estados independientes respecto de sus poblaciones colonizadas. En América Latina: "Internal colonialism and national development" (González Casanova, 1965) y "Classes, colonialism and acculturation" (Stavenhagen, 1965); fueron seguramente los más importantes entre quienes trataron de teorizar el problema de manera sistemática. Ahora sabemos que esos son problemas acerca de la colonialidad que van mucho más allá de la trama institucional del Estado-nación. 
cia no lo fueron por mucho tiempo. Los esclavos negros fueron de importancia básica para la economía, pero demográficamente fueron una minoría. Y desde el comienzo, después de la Independencia, la producción fue hecha en gran medida por trabajadores asalariados y productores independientes. En Chile, durante el período colonial, la servidumbre india fue restringida, ya que los sirvientes indios locales eran una pequeña minoría. Y los esclavos negros, a pesar de ser más importantes para la economía, eran también una pequeña minoría. De este modo, esas razas no eran una gran fuente de trabajo gratuito como en el caso de los demás países ibéricos. Consecuentemente, desde el inicio de la Independencia una creciente proporción de la producción local hubo de estar basada en el salario y el capital, y por esa razón el mercado interno fue vital para la burguesía pre monopólica. Así, para las clases dominantes de ambos países -toutes distances gardées- el trabajo asalariado local, la producción y el mercado interno fueron preservados y protegidos de la competencia externa como la única y la más importante fuente de beneficio capitalista. Aún más, el mercado interno tuvo que ser expandido y protegido. En ese sentido, había algunas áreas de intereses comunes entre los trabajadores asalariados, los productores independientes y la burguesía local. Esto, en consecuencia, con las limitaciones derivadas de la exclusión de negros y mestizos, era un interés nacional para la gran mayoría de la población del nuevo Estado-nación.

\section{ESTADO INDEPENDIENTE Y SOCIEDAD COLONIAL: DEPENDENCIA HISTÓRICO- ESTRUCTURAL}

En cambio, en las otras sociedades iberoamericanas, la pequeña minoría blanca en el control de los Estados independientes y las sociedades coloniales no podía haber tenido, ni sentido, ningún interés social en común con los indios y negros y mestizos. Al contrario, sus intereses sociales eran explícitamente antagónicos respecto de los siervos indios y los esclavos negros, dado que sus privilegios estuvieron, precisamente, hechos del dominio / explotación de dichas gentes. De modo que no había ningún terreno de intereses comunes entre blancos y no blancos $\mathrm{y}$, en consecuencia, ningún interés nacional común a todos ellos. Por eso, desde el punto de vista de los dominadores, sus intereses sociales estuvieron mucho más cerca de los intereses de sus pares europeos y en consecuencia estuvieron siempre inclinados a se- 
guir los intereses de la burguesía europea. Eran pues, dependientes.

Eran dependientes de esa manera específica, no porque estuvieran subordinados por un mayor poder económico o político. ¿De quién? España o Portugal eran entonces demasiado débiles, se subdesarrollaban, no podían ejercer ningún neocolonialismo como ingleses o franceses en ciertos países de África después de la independencia política de esos países. Estados Unidos estaba absorbido en la conquista de las tierras de los indios y en el exterminio de esa población, iniciando su expansión imperial sobre parte del Caribe, sin capacidad aún de expandir su dominio económico o político más allá. Inglaterra intentó la ocupación de Buenos Aires y fue derrotada.

Los señores blancos latinoamericanos, dueños del poder político y de siervos y de esclavos, no tenían intereses comunes, sino exactamente antagónicos a los de esos trabajadores, que eran la abrumadora mayoría de la población de los nuevos Estados. Y mientras en Europa y Estados Unidos la burguesía blanca expandía la relación social llamada capital como eje de articulación de la economía y de la sociedad, los señores latinoamericanos no podían acumular sus cuantiosos beneficios comerciales comprando fuerza de trabajo asala- riada, precisamente porque eso iba en contra de la reproducción de su señorío. Y destinaban esos beneficios comerciales al consumo ostentoso de las mercancías producidas, sobre todo, en Europa.

La dependencia de los capitalistas señoriales de esos países tenía, en consecuencia, una fuente inescapable: la colonialidad de su poder los llevaba a percibir sus intereses sociales como iguales a los de los otros blancos dominantes, en Europa y en Estados Unidos. Esa misma colonialidad del poder les impedía, sin embargo, desarrollar realmente sus intereses sociales en la misma dirección que los de sus pares europeos, esto es, convertir capital comercial (beneficio producido lo mismo en la esclavitud, en la servidumbre, o en la reciprocidad) en capital industrial, puesto que eso implicaba liberar indios siervos y esclavos negros y convertirlos en trabajadores asalariados. Por obvias razones, los dominadores coloniales de los nuevos Estados independientes, en especial en América del Sur después de la crisis de fines del siglo XVIII, no podían ser en esa configuración sino socios menores de la burguesía europea. Cuando mucho más tarde fue preciso liberar a los esclavos, no fue para asalariarlos, sino para reemplazarlos por trabajadores inmigrantes de otros países, europeos y 
asiáticos. La eliminación de la servidumbre de los indios es reciente. No había ningún interés social común, ningún mercado propio que defender, lo que habría incluido el salariado, ya que ningún mercado local era de interés de los dominadores. No había, simplemente, ningún interés nacional.

La dependencia de los señores capitalistas no provenía de la subordinación nacional. Esta fue, por el contrario, la consecuencia de la comunidad de intereses raciales. Estamos tratando aquí con el concepto de la dependencia histórico-estructural, que es muy diferente de las propuestas nacionalistas de la dependencia externa o estructural ${ }^{40}$. La subordinación vino más adelante, precisamente debido a la dependencia y no a la inversa: durante la crisis económica mundial de los treinta, la burguesía con más capital comercial de América Latina (Argentina, Brasil, México, Chile, Uruguay y, hasta cierto punto, Colombia) fue forzada a producir localmente los bienes que servían para su consumo ostentoso y que antes tenían que importar. Este fue el inicio del peculiar camino

40 Véase, sobre este aspecto, mi "Urbanización, cambio social y dependencia" (Quijano, 1967), publicado en el libro de Cardoso y Weffort América Latina. Ensayos de interpretación sociológica. latinoamericano de industrialización dependiente: la sustitución de los bienes importados para el consumo ostentoso de los señores y de sus pequeños grupos medios asociados, por productos locales destinados a ese consumo. Para esa finalidad no era necesario reorganizar globalmente las economías locales, asalariar masivamente a siervos, ni producir tecnología propia. La industrialización a través de la sustitución de importaciones es, en América Latina, un caso diáfano de las implicaciones de la colonialidad del poder ${ }^{41}$.

En este sentido, el proceso de independencia de los Estados en América Latina sin la descolonización de la sociedad no pudo ser, no fue, un proceso hacia el desarrollo de los Estadosnación modernos, sino una rearticulación de la colonialidad del poder sobre nuevas bases institucionales. Desde entonces, durante casi 200 años, hemos estado ocupados en el intento de avanzar en el camino de la nacionalización de nuestras sociedades y nuestros Estados. Todavía, en ningún país latinoamericano es posible encontrar una sociedad plenamente nacionalizada ni tampoco un genuino Estado-nación.

41 Sobre estas cuestiones he adelantado algunas propuestas de debate en "América Latina en la economía mundial" (Quijano, 1993). 
La homogeneización nacional de la población, según el modelo eurocéntrico de nación, sólo hubiera podido ser alcanzada a través de un proceso radical y global de democratización de la sociedad y del Estado. Primero que nada, esa democratización hubiera implicado, y aún debe implicar, el proceso de la descolonización de las relaciones sociales, políticas y culturales entre las razas, o más propiamente entre grupos y elementos de existencia social europeos y no europeos. No obstante, la estructura de poder fue y aún sigue estando organizada sobre y alrededor del eje colonial. La construcción de la nación y sobre todo del Estado-nación han sido conceptualizadas y trabajadas en contra de la mayoría de la población, en este caso, de los indios, negros y mestizos. La colonialidad del poder aún ejerce su dominio, en la mayor parte de América Latina, en contra de la democracia, la ciudadanía, la nación y el Estadonación moderno.

Actualmente se puede distinguir cuatro trayectorias históricas y líneas ideológicas acerca del problema del Estado-nación:

1. Un limitado pero real proceso de descolonización / democratización a través de revoluciones radicales como en México y en Bolivia, después de las derrotas de Haití y de
Tupac Amaru. En México, el proceso de descolonización del poder empezó a verse paulatinamente limitado desde los sesenta hasta entrar finalmente en un período de crisis al final de los setenta. En Bolivia la revolución fue derrotada en 1965 .

2. Un limitado pero real proceso de homogeneización colonial (racial), como en el Cono Sur (Chile, Uruguay, Argentina), por medio de un genocidio masivo de la población aborigen. Una variante de esa línea es Colombia, en donde la población original fue cuasi exterminada durante la colonia y reemplazada con los negros.

3. Un siempre frustrado intento de homogeneización cultural a través del genocidio cultural de los indios, negros y mestizos, como en México, Perú, Ecuador, Guatemala-Centro América y Bolivia.

4. La imposición de una ideología de "democracia racial" que enmascara la verdadera discriminación y la dominación colonial de los negros, como en Brasil, Colombia y Venezuela. Difícilmente alguien puede reconocer con seriedad una verdadera ciudadanía de la población de origen africano en esos países, aunque las tensiones y conflictos raciales no son tan violentos y explícitos como en Sudáfrica o en el sur de los Estados Unidos. 
Lo que estas comprobaciones indican es que hay, sin duda, un elemento que impide radicalmente el desarrollo y culminación de la nacionalización de la sociedad y del Estado, en la misma medida en que impide su democratización, puesto que no se encuentra ningún ejemplo histórico de modernos Estado-nación que no sean el resultado de dicha democratización social y política. ¿Cuál es o puede ser ese elemento?

En el mundo europeo, y por eso en la perspectiva eurocéntrica, la formación de Estadosnación ha sido teorizada, imaginada en verdad, como expresión de la homogeneización de la población en términos de experiencias históricas comunes. Y a primera vista, los casos exitosos de nacionalización de sociedades y Estados en Europa parecen darle la razón a ese enfoque. Lo que encontramos en la historia conocida es, desde luego, que esa homogeneización consiste en la formación de un espacio común de identidad y de sentido para la población de un espacio de dominación. $\mathrm{Y}$ eso, en todos los casos, es el resultado de la democratización de la sociedad, la cual de ese modo puede organizarse y expresarse en un Estado democrático. La pregunta pertinente, a estas alturas del debate, es ¿por qué eso ha sido posible en Europa Occidental, y con las limitaciones sabidas, en todo el mundo de identidad europea (Canadá, EE.UU., Australia, Nueva Zelandia, por ejemplo)? ¿Por qué no ha sido posible, hasta hoy sino de modo parcial y precario, en América Latina?

Para empezar, ¿hubiera sido posible en Francia, el caso clásico de Estado-nación moderno, esa democratización social y radical si el factor racial hubiera estado incluido? Es muy poco probable. Hoy en día es fácil observar en Francia el problema nacional y el debate producido por la presencia de población no-blanca, originaria de las ex colonias francesas. Obviamente, no es un asunto de etnicidad ni creencias religiosas. Nuevamente basta con recordar que un siglo atrás el caso Dreyfus demostró la capacidad de discriminación de los franceses, pero su final también demostró que para muchos de ellos la identidad de origen no era requisito determinante para ser miembro de la nación francesa, hasta tanto el color fuera francés. Los judíos franceses son hoy más franceses que los hijos de africanos, árabes y latinoamericanos nacidos en Francia. Esto, para no mencionar lo sucedido con los inmigrantes rusos y españoles cuyos hijos, por haber nacido en Francia, son franceses.

Esto quiere decir que la colonialidad del poder, basada en la imposición de la idea de 
raza como instrumento de dominación, ha sido siempre un factor limitante de estos procesos de construcción del Estado-nación basados en el modelo eurocéntrico, sea en menor medida como en el caso norteamericano o de modo decisivo como en América Latina. El grado actual de limitación depende, como ha sido mostrado, de la proporción de las razas colonizadas dentro de la población total y de la densidad de sus instituciones sociales y culturales.

Por todo eso, la colonialidad del poder establecida sobre la idea de raza debe ser admitida como un factor básico en la cuestión nacional y del Estado-nación. El problema es, sin embargo, que en América Latina la perspectiva eurocéntrica fue adoptada por los grupos dominantes como propia, y los llevó a imponer el modelo europeo de formación del Estadonación para estructuras de poder organizadas alrededor de relaciones coloniales. Así aún nos encontramos hoy en un laberinto donde el Minotauro es siempre visible, pero ninguna Ariadna para mostrarnos la ansiada salida.

\section{EUROCENTRISMO Y REVOLUCIÓN EN AMÉRICA LATINA}

Otro caso claro de ese trágico desencuentro entre nuestra experiencia y nuestra perspecti- va de conocimiento es el debate y la práctica de proyectos revolucionarios. En el siglo XX la abrumadora mayoría de la izquierda latinoamericana, adherida al materialismo histórico, ha debatido básicamente en torno a dos tipos de revoluciones: democrático-burguesa o socialista. Rivalizando con esa izquierda, el movimiento denominado aprista -el APRA (Alianza Popular Revolucionaria Antiimperialista) en el Perú; $\mathrm{AD}$ (Acción Democrática en Venezuela); MNR (Movimiento Nacionalista Revolucionario) en Bolivia; MLN (Movimiento de Liberación Nacional) en Costa Rica; Movimiento Revolucionario Auténtico y los Ortodoxos en Cuba, entre los más importantes- por boca de su mayor teórico, el peruano Haya de la Torre, propuso originalmente, entre 1925-1935, la llamada Revolución antiimperialista, como un proceso de depuración del carácter capitalista de la economía y de la sociedad latinoamericanas, sobre la base del control nacional-estatal de los principales recursos de producción, como una transición hacia una revolución socialista. Desde el fin de la Segunda Guerra Mundial, ese proyecto transitó definitivamente a una suerte de socialliberalismo ${ }^{42}$, y se va agotando de ese modo.

42 La miopía eurocéntrica, no sólo de estudiosos de Europa o de Estados Unidos sino también de los de 
De manera breve y esquemática, pero no arbitraria, se puede presentar el debate latinoamericano sobre la revolución democrático-burguesa como un proyecto en el cual la burguesía organiza a la clase obrera, a los campesinos y a otros grupos dominados para arrancar al señorío feudal del control del Estado, y para reorganizar la sociedad y el Estado en los términos del capital y de la burguesía. El supuesto central de ese proyecto es que la sociedad en América Latina es, en lo fundamental, feudal, o a lo sumo semifeudal, ya que el capitalismo es aún incipiente, marginal y subordinado. La revolución socialista, en cambio, se concibe como la erradicación de la burguesía del control del Estado por la clase obrera, la clase trabajadora por excelencia, a la cabeza de una coalición de las clases explotadas y dominadas, para imponer el control estatal de los medios de producción, y construir desde el Estado la nueva sociedad. El supuesto de esa propuesta es, obviamente,

América Latina, ha difundido y cuasi impuesto universalmente el nombre de populismo para esos movimientos y proyectos que, sin embargo, tienen poco en común con el movimiento de los narodnikis rusos del siglo XIX o del populismo norteamericano posterior. Una discusión de estas cuestiones en mi texto "Fujimorismo y populismo" (Quijano, 1998a), publicado en el libro de De Lara El fantasma del populismo. que la economía, y por lo tanto, la sociedad y el Estado en América Latina son básicamente capitalistas. En su lenguaje, eso implica que el capital como relación social de producción es ya dominante y que, en consecuencia, lo burgués es también dominante en la sociedad y en el Estado. Admite que hay rezagos feudales y en consecuencia tareas democrático-burguesas en el trayecto de la revolución socialista.

De hecho, el debate político del último medio siglo en América Latina ha estado anclado en si la economía, la sociedad y el Estado eran feudales / semifeudales o capitalistas. La mayor parte de la izquierda latinoamericana, hasta hace pocos años, adhería a la propuesta democrático-burguesa; siguiendo ante todo los lineamientos centrales del socialismo real o campo socialista, sea con sede en Moscú o en Pekín.

Para creer que en América Latina una revolución democrático-burguesa basada en el modelo europeo es no sólo posible, sino necesaria, primero es preciso admitir en América, y más precisamente en América Latina: 1) la relación secuencial entre feudalismo y capitalismo; 2) la existencia histórica del feudalismo y en consecuencia el conflicto histórico antagónico entre la aristocracia feudal y la burguesía; 3) una burguesía interesada en llevar a cabo semejante empresa revolucionaria. Sabe- 
mos que en China a inicios de los treinta, Mao propuso la idea de la revolución democrática de nuevo tipo, porque la burguesía ya no está interesada en, y tampoco es capaz de llevar a cabo, esa, su misión histórica. En este caso, una coalición de clases explotadas / dominadas, bajo el liderazgo de la clase trabajadora, debe sustituir a la burguesía y emprender la nueva revolución democrática.

En América, sin embargo, como en escala mundial desde hace 500 años, el capital ha existido sólo como el eje dominante de la articulación conjunta de todas las formas históricamente conocidas de control y explotación del trabajo, configurando así un único patrón de poder, histórico-estructuralmente heterogéneo, con relaciones discontinuas y conflictivas entre sus componentes. Ninguna secuencia evolucionista entre los modos de producción, ningún feudalismo anterior, separado y antagónico del capital, ningún señorío feudal en el control del Estado, al cual una burguesía urgida de poder tuviera que desalojar por medios revolucionarios. Si secuencia hubiera, es sin duda sorprendente que el movimiento seguidor del materialismo histórico no haya luchado por una revolución antiesclavista, previa a la revolución antifeudal, previa a su vez a la revolución anticapitalista. Porque en la mayor par- te de este continente (EE.UU., todo el Caribe, incluyendo Venezuela, Colombia, las costas de Ecuador y Perú, Brasil), el esclavismo ha sido más extendido y más poderoso. Pero, claro, la esclavitud terminó antes del siglo XX. Y fueron los señores feudales los que heredaron el poder. ¿No es verdad?

Una revolución antifeudal, ergo democrático-burguesa, en el sentido eurocéntrico ha sido, pues, siempre, una imposibilidad histórica. Las únicas revoluciones democráticas realmente ocurridas en América (aparte de la Revolución americana) han sido las de México y de Bolivia, como revoluciones populares, nacionalistas-antiimperialistas, anticoloniales, esto es contra la colonialidad del poder, y antioligárquicas, esto es contra el control del Estado por la burguesía señorial bajo la protección de la burguesía imperial. En la mayoría de los otros países, el proceso ha sido un proceso de depuración gradual y desigual del carácter social, capitalista, de la sociedad y el Estado. En consecuencia, el proceso ha sido siempre muy lento, irregular y parcial.

¿Podría haber sido de otra manera? Toda democratización posible de la sociedad en América Latina debe ocurrir en la mayoría de estos países, al mismo tiempo y en el mismo movimiento histórico como una descolonización y 
como una redistribución del poder. En otras palabras, como una redistribución radical del poder. Esto es debido, primero, a que las "clases sociales", en América Latina, tienen "color", cualquier "color" que pueda encontrarse en cualquier país, en cualquier momento. Eso quiere decir, definitivamente, que la clasificación de las gentes no se realiza solamente en un ámbito del poder, la economía, por ejemplo, sino en todos y en cada uno de los ámbitos. La dominación es el requisito de la explotación, y la raza es el más eficaz instrumento de dominación que, asociado a la explotación, sirve como el clasificador universal en el actual patrón mundial de poder capitalista. En términos de la cuestión nacional, sólo a través de ese proceso de democratización de la sociedad puede ser posible y finalmente exitosa la construcción de un Estado-nación moderno, con todas sus implicancias, incluyendo la ciudadanía y la representación política.

En cuanto al espejismo eurocéntrico acerca de las revoluciones "socialistas", como control del Estado y como estatización del control del trabajo / recursos / productos, de la subjetivi$\mathrm{dad} /$ recursos / productos, del sexo / recursos / productos, esa perspectiva se funda en dos supuestos teóricos radicalmente falsos. Primero, la idea de una sociedad capitalista homogénea, en el sentido de que sólo el capital como relación social existe y en consecuencia la clase obrera industrial asalariada es la parte mayoritaria de la población. Pero ya hemos visto que así no ha sido nunca, ni en América Latina, ni en el resto del mundo, y que casi seguramente así no ocurrirá nunca. Segundo, la idea de que el socialismo consiste en la estatización de todos y cada uno de los ámbitos del poder y de la existencia social, comenzando con el control del trabajo, porque desde el Estado se puede construir la nueva sociedad. Ese supuesto coloca toda la historia, de nuevo, sobre su cabeza. Inclusive en los toscos términos del materialismo histórico, hace de una superestructura, el Estado, la base de la sociedad. Y escamotea el hecho de una total reconcentración del control del poder, lo que lleva necesariamente al total despotismo de los controladores, haciéndola aparecer como si fuera una socialización del poder, esto es la redistribución radical del control del poder. Pero, precisamente, el socialismo no puede ser otra cosa que la trayectoria de una radical devolución del control sobre el trabajo / recursos / productos, sobre el sexo / recursos / productos, sobre la autoridad / instituciones / violencia, y sobre la intersubjetividad / conocimiento / comunicación, a la vida 
cotidiana de las gentes. Eso es lo que propongo, desde 1972, como socialización del poder ${ }^{43}$.

Solitariamente, en 1928, José Carlos Mariátegui fue sin duda el primero en vislumbrar, no sólo en América Latina, que en este espacio / tiempo las relaciones sociales de poder, cualquiera que fuera su carácter previo, existían y actuaban simultánea y articuladamente, en una única y conjunta estructura de poder; que ésta no podía ser una unidad homogénea, con relaciones continuas entre sus elementos, moviéndose en la historia continua y sistémicamente. Por lo tanto, que la idea de una revolución socialista tenía que ser, por necesidad histórica, dirigida contra el conjunto de ese poder y que lejos de consistir en una nueva reconcentración burocrática del poder, sólo podía tener sentido como redistribución entre las gentes, en su vida cotidiana, del control sobre las condiciones de su existencia social ${ }^{44}$. El debate no

43 Véanse: “¿Qué es y qué no es el socialismo?" (Quijano, 1972); "Poder y democracia en el socialismo" (Quijano, 1981).

44 Ese descubrimiento es, sin duda, lo que otorga a Mariátegui su mayor valor y su continuada vigencia, derrotados los socialismos y su materialismo histórico. Véase, sobre todo, el tramo final del primero de sus 7 ensayos de interpretación de la realidad peruana será retomado en América Latina sino a partir de los años sesenta del siglo que recién terminó, y en el resto del mundo a partir de la derrota mundial del campo socialista.

En realidad, cada categoría usada para caracterizar el proceso político latinoamericano ha sido siempre un modo parcial y distorsionado de mirar esta realidad. Esa es una consecuencia inevitable de la perspectiva eurocéntrica, en la cual un evolucionismo unilineal y unidireccional se amalgama contradictoriamente con la visión dualista de la historia; un dualismo nuevo y radical que separa la naturaleza de la sociedad, el cuerpo de la razón; que no sabe qué hacer con la cuestión de la totalidad, negándola simplemente, como el viejo empirismo o el nuevo posmodernismo, o entendiéndola sólo de modo organicista o sistémico, convirtiéndola así en una perspectiva distorsionante, imposible de ser usada salvo para el error.

No es, pues, un accidente que hayamos sido, por el momento, derrotados en ambos

(Mariátegui, 1928; numerosas ediciones); "Punto de vista Antiimperialista" (Mariátegui, 1974), presentado en la Primera Conferencia Comunista Latinoamericana, Buenos Aires, junio de 1929; y el célebre editorial de la revista Amauta "Aniversario y balance" (Mariátegui, 1928). 
proyectos revolucionarios, en América y en todo el mundo. Lo que pudimos avanzar y conquistar en términos de derechos políticos y civiles, en una necesaria redistribución del poder, de la cual la descolonización de la sociedad es presupuesto y punto de partida, está ahora siendo arrasado en el proceso de reconcentración del control del poder en el capitalismo mundial y con la gestión de los mismos funcionarios de la colonialidad del poder. En consecuencia, es tiempo de aprender a liberarnos del espejo eurocéntrico donde nuestra imagen es siempre, necesariamente, distorsionada. Es tiempo, en fin, de dejar de ser lo que no somos.

\section{REFERENCIAS BIBLIOGRÁFICAS}

Allen, Theodore W. 1994 The Invention of White Race (Londres: Verso) 2 Vols.

Amin, Samir 1989 Eurocentrism (Nueva York: Monthly Review Press).

Anderson, Benedict 1991 Imagined Communities (Londres: Verso).

Baer, Werner 1962 "The Economics of Prebisch and ECLA" en Economic Development and Cultural Change, Vol. X, ene.
Blaut, J. M. 1993 The Colonizers Model of the World. Geographical Diffusionism and Eurocentric History (Nueva York: The Guilford Press).

Bousquié, Paul 1994 Le corps cet inconnu (París: L'Harmattan).

Coronil, Fernando 1996 "Beyond

Occidentalism: Toward Nonimperial

Geohistorical Categories" en Cultural Anthropology, Vol. 11, $\mathrm{N}^{\circ}$ 1, feb.

Descartes, René 1967 "Méditations" y "Description du corps humain" en Oeuvres philosophiques (París: Alquie).

Descartes, René 1637 Discours de la méthode (París: ediciones varias).

Dussel, Enrique 1995 The Invention of the Americas (Nueva York: Continuum).

ECLA (CEPAL) 1960 The Economic Development in Latin America and its Principal Problems (Nueva York: United Nations).

Gobineau, Arthur de 1857 (1853) Essais sur l'inégalité des races humaines (París: s/d). González Casanova, Pablo 1965 "Internal Colonialism and National Development" en Studies in Comparative International Development, Vol. $1, \mathrm{~N}^{\circ} 4$.

Gruzinski, Serge 1988 La colonisation de l'imaginaire. Sociétés indigènes 
et occidentalisation dans le Mexique espagnol XVI-XVIII siècle (París: Gallimard) [Edición en español: La colonización de lo imaginario. Sociedades indigenas y occidentalización en el México español. Siglos XVI-XVIII (México: FCE, 1995)].

Hopkins, Terence y Wallerstein, Immanuel 1982 World-Systems Analysis. Theory and Methodology (Beverly Hills: Sage) Vol. 1.

Imaz, Eugenio 1964 Nosotros mañana (Buenos Aires: Sudamericana).

Jacobson, Mathew Frye 1998 Whiteness of a Different Color (Cambridge: Harvard University Press).

Jonathan, Mark 1994 Human Biodiversity, Genes, Race and History (Nueva York: Aldyne de Gruyter).

Lander, Edgardo 1997 "Colonialidad, modernidad, postmodernidad" en Anuario Mariateguiano (Lima), Vol. IX, $\mathrm{N}^{\circ} 9$.

Mariátegui, José Carlos 1974 (1929) "Punto de Vista Antiimperialista" en Ideología y Política (Lima: Biblioteca Amauta) Vol. 11, Serie Obras completas [Originalmente, presentado en la Primera Conferencia Comunista Latinoamericana, Buenos Aires, junio de 1929].
Mariátegui, José Carlos 19287 ensayos de interpretación de la realidad peruana (ediciones varias).

Mariátegui, José Carlos 1928 “Aniversario y balance” Amauta (Lima), Editorial de la revista, sep.

Mark, Jonathan 1994 Human Biodiversity, Genes, Race and History (Nueva York: Aldyne de Gruyter).

Mignolo, Walter 1995 The Darker Side of the Renaissance. Literacy, Territoriality and Colonization (Ann Arbor: Michigan University Press).

Mudimbe, V. Y. 1988 The Invention of Africa. Gnosis, Philosophy and the Order of Knowledge (Bloomington: Bloomington University Press).

Myrdall, Gunnar 1944 American Dilemma (Nueva York: Harper and Brothers).

O'Gorman, Edmundo 1954 La invención de América (México: FCE).

Prebisch, Raúl 1959 "Commercial Policy in the Underdeveloped Countries" en American Economic Review, Vol. XLIX, Papers and Proceedings, mayo.

Prebisch, Raúl 1960 The Economic Development in Latin America and its Principal Problems (Nueva York: ECLA / United Nations). 
Quijano, Aníbal 2000 "Colonialidad del poder, eurocentrismo y América Latina" en Lander, Edgardo (comp.) La colonialidad del saber: eurocentrismo y ciencias sociales. Perspectivas latinoamericanas (Buenos Aires: CLACSO) p. 246. En: <http:// bibliotecavirtual.clacso.org.ar/ar/libros/ lander/quijano.rtf>.

Quijano, Aníbal 2000a "El fantasma del desarrollo en América Latina" en Revista venezolana de economía y ciencias sociales (Caracas), $\mathrm{N}^{\circ} 2$.

Quijano, Aníbal 2000b "Modernidad y democracia: intereses y conflictos" en Anuario Mariateguiano (Lima), Vol. XII, $\mathrm{N}^{\circ} 12$.

Quijano, Aníbal 1999 "Coloniality of power and its institutions”, Ensayo presentado en el Simposio sobre Colonialidad del poder y sus ámbitos sociales, Binghamton University, Binghamton, Nueva York, abril (mimeo).

Quijano, Aníbal 1999a “iQué tal raza!” en Familia y cambio social (Lima: CECOSAM).

Quijano, Aníbal 1998 "Estado-nación, ciudadanía y democracia: cuestiones abiertas" en González, Helena y Schmidt, Heidulf (eds.) Democracia para una nueva sociedad (Caracas: Nueva Sociedad).

Quijano, Aníbal 1998a "Fujimorismo y populismo" en De Lara, Burbano (ed.) $E l$ fantasma del populismo (Caracas: Nueva Sociedad).

Quijano, Aníbal 1997 "Colonialidad del poder, cultura y conocimiento en América Latina" en Anuario Mariateguiano (Lima), Vol. IX, $\mathrm{N}^{\circ} 9$.

Quijano, Aníbal 1994 "Colonialité du Pouvoir, Démocratie et Citoyenneté en Amérique Latine" en Amérique Latine: Démocratie et Exclusion (París: L'Harmattan).

Quijano, Aníbal 1993 “América Latina en la economía mundial" en Problemas del desarrollo (México: UNAM), Vol. XXIV, ${ }^{\circ}$ 95, oct.- dic.

Quijano, Aníbal 1992a “'Raza', 'etnia' y 'nación' en Mariátegui: cuestiones abiertas" en Forgues, Roland (ed.) José Carlos Mariátegui y Europa. La otra cara del descubrimiento (Lima: Amauta).

Quijano, Aníbal 1992b "Réflexions sur l'Interdisciplinarité, le Développement et les Relations Inter culturelles" en Entre Savoirs. Interdisciplinarité en acte: enjeux, obstacles, résultats (París: UNESCO / ERES). 
Quijano, Aníbal 1991 "América, el capitalismo y la modernidad nacieron el mismo día” en ILLA (Lima), $\mathrm{N}^{\circ} 10$, ene.

Quijano, Aníbal 1991a "Colonialidad y modernidad / racionalidad" en Perú Indígena (Lima), Vol. 13, $\mathrm{N}^{\circ} 29$.

Quijano, Aníbal 1988 "La nueva heterogeneidad estructural de América Latina" en Sonntag, Heinz (ed.) Nuevos temas, nuevos contenidos (Caracas: UNESCO / Nueva Sociedad).

Quijano, Aníbal 1988a "Modernidad, identidad y utopía en América Latina”. (Lima: Sociedad y Política Ediciones).

Quijano, Aníbal 1981 "Poder y democracia en el socialismo" (Lima: Sociedad y Política).

Quijano, Aníbal 1972 “¿Qué es y qué no es el socialismo?" (Lima: Sociedad y Política).

Quijano, Aníbal 1967 "Urbanización, cambio social y dependencia" en Cardoso, Fernando Henrique y Weffort, Francisco (eds.) América Latina. Ensayos de interpretación sociológica (Santiago de Chile: Editorial Universitaria).

Quijano, Aníbal 1966 "Notas sobre el concepto de marginalidad social" (Santiago de Chile: CEPAL). [Publicado también en el volumen: Quijano, Aníbal 1977 Imperialismo y marginalidad en América Latina (Lima: Mosca Azul)].

Quijano, Aníbal y Wallerstein, Immanuel 1992 "Americanity as a Concept or the Americas in the Modern World-System" en International Social Science Journal (París: UNESCO), $\mathrm{N}^{\circ} 134$, nov.

Rabasa, José 1993 Inventing America. Spanish Historiography and the Formation of Eurocentrism (Norman: Oklahoma University Press).

Said, Edward 1979 Orientalism (Nueva York: Vintage Books)

Samir, Amin 1989 Eurocentrism (Nueva York: Monthly Review Press).

Stavenhagen, Rodolfo 1965 "Classes, colonialism and acculturation" en Studies in Comparative International Development, Vol. 1, $\mathrm{N}^{\circ} 7$.

Stocking, George W. Jr. 1968 Race, Culture and Evolution. Essays in the History of Anthropology (Nueva York: The Free Press).

Tilly, Charles 1990 Coercion, Capital and European States A.D. 990-1992 (Cambridge: Blackwell).

Tocqueville, Alexis de 1835 Democracy in America (ediciones varias) [Edición en español: La democracia en América (Madrid: Alianza, 1980)]. 
Viola, Herman y Margolis, Carolyn (eds.) 1991 Seeds of Change. A Quincentennial Commemoration (Washington: Smithsonian Institute Press).

Wallerstein, Immanuel 1989 (1974) The Modern World-System (Nueva York: Academic Press) 3 Vols.
Wallerstein, Immanuel 1997 "El espacio / tiempo como base del conocimiento" en Anuario Mariateguiano (Lima), Vol. IX, $\mathrm{N}^{\circ} 9$.

Young, Robert C. 1995 Colonial Desire. Hybridity in Theory, Culture and Race (Londres: Routledge). 